THE UNIVERSITY OF MANITOBA

\author{
ME'CHANISMS OF BUOYANCY ADJUSTMENT AND EFFECTS OF \\ WATER VELOCITY AND TEMPERATURE ON ABILITY TO MAINTAIN \\ BUOYANCY IN FATHEAD MINNOWS, PIMEPHALES PROMELAS, RAFINESQUE
}

BY

D. BRUCE STEWART

\begin{abstract}
A THESIS
SUBMITTED TO THE FACULTY OF GRADUATE STUDIES

IN PARTIAL FULFILLMENT OF THE REQUIREMENTS

FOR THE DEGREE OF MASTER OF SCIENCE

DEPARTMENT OF ZOOLOGY
\end{abstract}

WINNIPEG, NANITOBA

April, 1980 


\section{MECHANISMS OF BUOYANCY ADJUSTMENT AND EFFECTS OF \\ WATER VELOCITY AND TEMPERATURE ON ABILITY TO MAINTAIN \\ BUOYANCY IN FATHEAD MINNOWS, PIMEPHALES PROMELAS, RAFINESQUE}

BY

DAVID BRUCE STEWART

A thesis submitted to the Faculty of Graduate Studies of

the University of Manitoba in partial fulfillment of the requirements of the degree of

MASTER OF SCIENCE

(c) 1980

Permission has been granted to the LIBRARY OF THE UNIVER-

SITY OF MANITOBA to lend or sell copies of this thesis. to the NATIONAL LIBRARY OF CANADA to microfilm this thesis and to lend or sell copies of the film, and UNIVERSITY' MICROFILMS to publish an abstract of this thesis.

The author reserves other publication rights, and neither the thesis nor extensive extracts from it may be printed or otherwise reproduced without the author's written permission. 


\begin{abstract}
Physostomous fathead minnows (Pimephales promelas) were observed to determine (1) the relative importance of gas secretion/absorption and gulping/spitting as mechanisms of buoyancy adjustment, and (2) the effects of water velocity and temperature on ability to maintain a minimum buoyancy in current for an extended time. Buoyancy is increased quickly by gulping air and slowly by secreting $\mathrm{O}_{2}$ and $\mathrm{CO}_{2} \cdot$ Small fish can increase buoyancy faster than large fish $\left(0.048 \mathrm{cf} .0 .028 \mathrm{~mL} \cdot \mathrm{g}^{-1} \cdot \mathrm{h}^{-1}\right)$. Relative contributions of gulping and secretion to buoyancy increases depend on the environmental conditions, and gulping appears to account for about $70 \%$ of any increase. Buoyancy is reduced quickly by spitting gas or slowly by resorbing $\mathrm{O}_{2}$ and $\mathrm{CO}_{2}$. Spitting is a fright response; resorption is the mechanism used to reduce swimbladder volume in response to an increase in water velocity. Small fish can reduce buoyancy by resorption faster than large fish $\left(0.034 \mathrm{cf} .0 .023 \mathrm{~mL} \cdot \mathrm{g}^{-1} \cdot \mathrm{h}^{-1}\right)$.

Except at $5^{\circ} \mathrm{C}$ and following the initial period of adjustment, buoyancy is maintained in current for at least 42 days. Buoyancy level is determined by water temperature and velocity. Effects of high and increasing temperature and velocity on buoyancy are antagonistic; the buoyancy
\end{abstract}


response to current being lost at high temperatures. At extreme temperatures and velocities, internal pressure is used to alter swimbladder volume, assisting in buoyancy regulation. Internal pressure may be a good indicator of stress. 
This thesis is dedicated to

my parents whose love and

encouragement have made my work so much easier. 


\section{ACKNOWLEDGEMENTS}

I thank my supervisor Dr. J. H. Gee for his support and guidance throughout this study and Maire Luoma for her valuable suggestions and help collecting fish. I thank Brian Knudson and Drs. B. Johnson and A. N. Arnason for their advice on statistical problems and Drs. S. G. Sealy, R. N. Sinha, and T. J. Wiens for their constructive criticism of the manuscript. Also, I thank Alyre Chiasson and the other graduate students of the Department for many helpful discussions and Mrs. B. Davies for typing the manuscript.

This research was supported by grants from the National Research Council of Canada. 
TABLE OF CONTENTS

PAGE

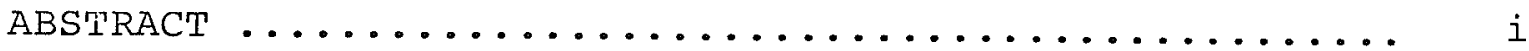

ACKNOWLEDGEMENTS $\ldots \ldots \ldots \ldots \ldots \ldots \ldots \ldots \ldots \ldots \ldots \ldots \ldots \ldots \ldots$

LIST OF FIGURES $\ldots \ldots \ldots \ldots \ldots \ldots \ldots \ldots \ldots \ldots \ldots \ldots \ldots \ldots \ldots$

LIST OF TABLES ....................... ix

INTRODUCTION $\ldots \ldots \ldots \ldots \ldots \ldots \ldots \ldots \ldots \ldots \ldots \ldots \ldots \ldots \ldots \ldots \ldots$

MATERIALS AND METHODS $\ldots \ldots \ldots \ldots \ldots \ldots \ldots \ldots \ldots \ldots \ldots$

Mechanism of Buoyancy Alteration ............ 5

Prediction of buoyancy from swimming

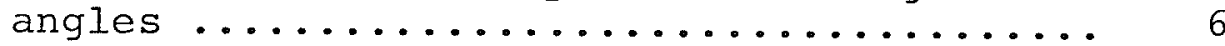

Buoyancy adjustment by spitting or

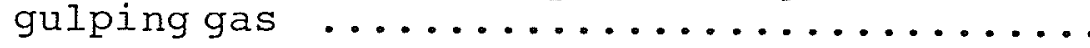

Buoyancy adjustment by resorption and secretion of gas $\ldots \ldots \ldots \ldots \ldots \ldots \ldots \ldots \ldots \ldots \ldots \ldots \ldots \ldots$

Relative contribution of gas gulping and secretion to buoyancy increases ......... 10

Ability to Maintain a Minimum Buoyancy ......... 11

Short term buoyancy maintenance ......... 11

Long term effects of water velocity ...... 12

Long term effects of water temperature .... 12

Effects of stress from temperature and

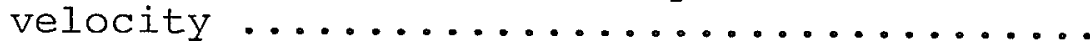

Statistical Analysis ................... 14

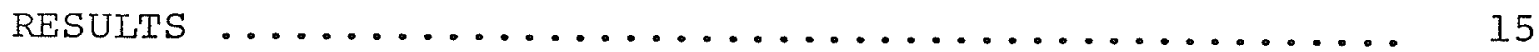

Mechanism of Buoyancy Alteration ........... 15

Prediction of buoyancy from swimming

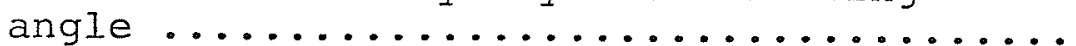


TABLE OF CONTENTS cont'à

PAGE

Buoyancy adjustment by spitting and

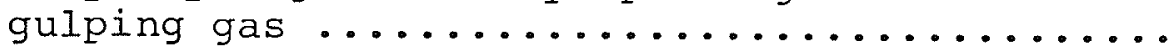

Buoyancy adjustment by resorption and

secretion of gas $\ldots \ldots \ldots \ldots \ldots \ldots \ldots \ldots \ldots \ldots$

Relative contribution of gas gulping and secretion to buoyancy increases ...........

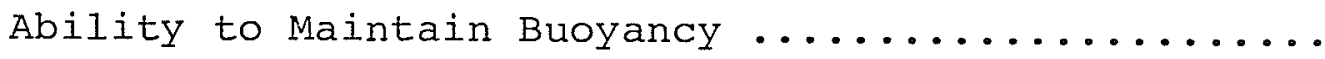

Short term buoyancy maintenance in still

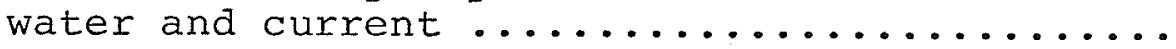

Long term effects of water temperature and velocity on buoyancy maintenance ..........

Effects of stress from temperature and water velocity on buoyancy maintenance ...........

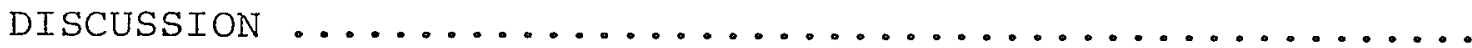

Mechanisms of Buoyancy Adjustment ............. 38

Ability to Maintain Buoyancy ................ 45

REFERENCES $\ldots \ldots \ldots \ldots \ldots \ldots \ldots \ldots \ldots \ldots \ldots \ldots \ldots \ldots \ldots \ldots \ldots \ldots \ldots$

APPENDICES $\ldots \ldots \ldots \ldots \ldots \ldots \ldots \ldots \ldots \ldots \ldots \ldots \ldots \ldots \ldots \ldots \ldots \ldots$ 


\section{LIST OF FIGURES}

PAGE

Figure 1 Bubble-free stream tank used for observing gas gulping and spitting behaviour and swimming angle of attack of fish in $20 \mathrm{~cm} \cdot \mathrm{s}^{-1}$ current or in still water .......

Figure 2 Niean buoyancy (solid circles; $\mathrm{n}=8$ ) and the percent of fish swimming horizontally (open cirlces) plotted for the first $12 \mathrm{~h}$ of adjustment to either current or still

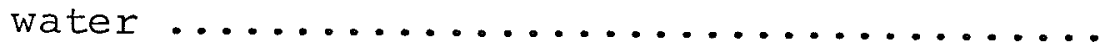

Figure 3 Regression analysis of mean buoyancy $(n=8)$ on percent of the fish swimming horizontally during the first $12 \mathrm{~h}$ of adjustment to current (solid circles) and still water (open circles) ....................

Figure 4 Frequency of spitting bubbles and surface gulping by fish when exposed to current for $24 \mathrm{~h}$ (buoyancy reduced) and then still water for $24 \mathrm{~h}$ (buoyancy increased). Buoyancy adjustment was complete when 95\% of the fish swam horizontally. Spitting and gulping occurring outside the period of buoyancy adjustment are indicated by solid bars ....

Figure 5 Percent of the swimbladder gas volume consisting of $\mathrm{N}_{2}, \mathrm{O}_{2}$, and $\mathrm{CO}_{2}$ and buoyancy in current and still water, with access to the surface (solid circles) and without (squares). Vertical lines are 95\% confidence intervals

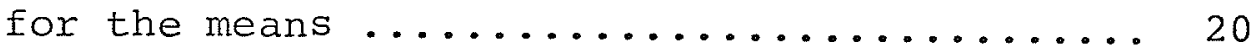


LIST OF FIGURES cont'd

PAGE

Figure 6 Progression of buoyancy alteration in

a fathead minnow using air gulping

(indicated by an arrow) and gas

secretion to increase buoyancy. Solid

lines indicate continuous observations,

dotted lines interpolations between

half-hourly observations ..............

Figure 7 Buoyancy (solid circles), standard volume

(open circles), and internal pressure

(crosses) measured over $48 \mathrm{~h}$ in still

water and current. Points are means

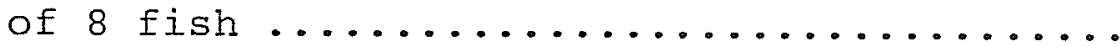

Figure 8 Nean buoyancies $(n=8)$ between 0 and 48 days in 10,20 and $30 \mathrm{~cm} \cdot \mathrm{s}^{-1}$ current at either

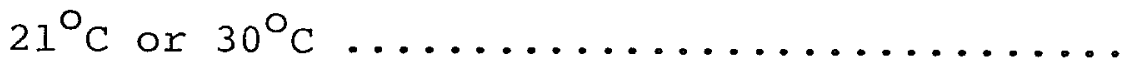

Figure 9 Effects of water velocity on mean $(n=40)$

buoyancy (solid circles), standard volume (open circles) and internal pressure (crosses) at $30^{\circ} \mathrm{C}$, between 10 and 42 days in current. Solid lines are significant ........... 27

Figure 10 Mean buoyancies $(n=8)$ between 0 and 42 days in $20 \mathrm{~cm} \cdot \mathrm{s}^{-1}$ current at $5^{\circ} \mathrm{C}$ (solid circles), $11^{\circ} \mathrm{C}$ (solid triangles), $21^{\circ} \mathrm{C}$ (crosses), $26^{\circ} \mathrm{C}$ (open triangles), and $30^{\circ} \mathrm{C}$ (open circles)... 29 
LIST OF FIGURES cont'd

Figure 11 Effect of time in current on mean $(n=40)$

buoyancy (solid circles), standard volume (open circles), and internal pressure

(crosses). Measurements are lumped for

all temperatures .................. 30

Figure 12 Effects of temperature on mean ( $n=64)$

buoyancy (solid circles), standard volume (open circles), and internal pressure

(crosses). Measurements are lumped over

time $(2-42$ d).$\ldots \ldots \ldots \ldots \ldots \ldots \ldots \ldots \ldots \ldots \ldots \ldots \ldots \ldots$

Figure 13 Regressions against time for buoyancy (solid circles), standard volume (open circles), and internal pressure (crosses) when water temperature and velocity are held constant. Solid lines are significant and points are included for the means $(n=8) \ldots \ldots \ldots \ldots \ldots \ldots \ldots \ldots \ldots \ldots \ldots \ldots \ldots \ldots$

Figure 14 Regressions against time for buoyancy (solid circles), standard volume (open circles), and internal pressure (crosses) when water temperature is increasing and velocity is constant. Solid lines are significant and points are included for the means $(n=8) \ldots \ldots$

Figure 15 Regressions against time for buoyancy (solid circles), standard volume (open circles), and internal pressure (crosses) when water temperature is constant and velocity is increasing. Solid lines are significant and points are included for the means $(n=8) \ldots \ldots \ldots \ldots \ldots \ldots \ldots \ldots \ldots$ 
LIST OF FIGURES cont'd

PAGE

Figure 16 Regressions against time for buoyancy (solid circles), standard volume (open circles), and internal pressure (crosses), when both water temperature and velocity are increasing. Solid lines are significant and points are included for the means

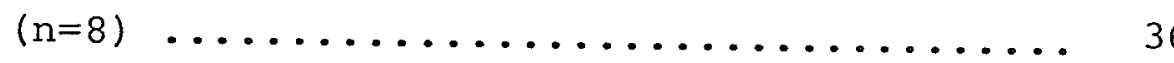

Figure 17 Variance of internal pressure measurements vs. mean internal pressure $(n=8)$ for:

I. constant water temperature and velocity, II. increasing temperature, III. increasing velocity, and IV. increasing water temperature and velocity. Solid lines are

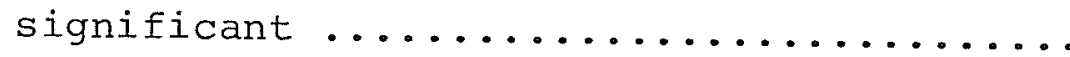

FIGURE Al Measured and predicted error in gas sample volume measurements arising from gas contraction and expansion with temperature changes and from errors in the pipette volume $\ldots \ldots \ldots \ldots \ldots \ldots \ldots \ldots \ldots \ldots \ldots \ldots$

\section{LIST OF TABLES}

Table 1 Contributions of gas gulping and secretion to buoyancy increases during the return to neutral buoyancy in still water ......... 22 


\section{INTRODUCTION}

The ability of fishes to adjust buoyancy by altering swimbladder volume is a common response to changes in water velocity (Gee et al., 1974; Gee and Gee, 1976). Plasticity in buoyancy permits efficient movement in waters where velocity and turbulence change in time and space. In current, a negative buoyancy and a benthic position help to prevent displacement downstream as the fish can counteract hydrodynamic lift and at the same time increase the frictional forces between the body and the substrate (Alexander, 1966; Gee, 1968). With a mid-water position in current, a reduced buoyancy appears to counteract hyảroaynamic lift from the shape of the body, maintaining vertical position and enabling locomotion with a minimum expenditure of energy (Berezay and Gee, 1978). In still water, a neutral buoyancy is advantageous for efficient maintenance of position and locomotion.

Buoyancy is affected by changes in photoperiod, water temperature and velocity, hydrostatic pressure, size and age of fish, degree of sexual development, and condition (Saunders, 1965; Neave et al., 1966; Gee, 1968, 1972, 1977; Pinder and Eales, 1969; Berezay and Gee, 1978; Luoma and Gee, 1980). Many of these factors interact. 
Little is known of the mechanisms of buoyancy adjustment in physostomes. Like physoclists, some alter their swimbladder volume by resorbing or secreting gas. Unlike physoclists they possess a pneumatic duct enabling them to exchange gas directly with the atmosphere by gulping air and passing it into the swimbladder or by forcing gas out of the swimbladder. Changes in internal pressure of the swimbladder gases may also be used to make minor corrections to buoyancy.

The ability to capitalize on buoyancy regulation depends upon the rate and extent of adjustment and the duration of maintenance of the appropriate level of buoyancy. Buoyancy changes in most stream fish are extensive, involving a 30-60\% reduction in swimbladder volume when current is encountered, and are rapid requiring $12-96 \mathrm{~h}$ for completion (Gee et al., 1974; Gee and Gee, 1976). However, little is known of the ability to maintain a minimum buoyancy in current for extended periods of time. Objectives of this study were to determine (I) the relative importance of secretion and absorption of gas versus gulping and spitting of gas as mechanisms of buoyancy adjustment, and (2) the effects of water velocity and temperature on the ability to maintain a minimum buoyancy. The physostomous fathead minnow (Pimephales promelas) was chosen as the subject for the study. It is comnon throughout most of central North 
America, inhabiting headwater streams and lakes (Scott and Crossman, 1973). In nature they are subject to wide variations in water temperature and velocity, especially during spring run-off (1-4 weeks). Their abundance and hardiness have made them a popular bioassay fish. 
MATERIALS AND METHODS

Fathead minnows were collected from the Pembina River, Manitoba as required. They were held in large fiberglass tanks $(170 \mathrm{~L})$ at either 5 or $11^{\circ} \mathrm{C}$ under a 12L:12D photoperiod and fed \#3 trout starter once a day. Prior to testing, fish were acclimated to the experimental temperature at a rate of no more than $1^{\circ} \mathrm{C} \cdot \mathrm{d}^{-1}$. Fish were not fed within 24 h of analysis.

To measure buoyancy, fish were captured by dipnet and anaesthetized in a solution of MS222 (ethyl m-aminobenzoate methanesulphonate). Swimbladder volume ( $\pm 0.001 \mathrm{~mL})$, weight of the gas-free fish in water $( \pm 0.001 \mathrm{~g}$; Sartorius balance model 2255), and the volume of gases released at atmospheric pressure $( \pm 0.001 \mathrm{~mL})$ were measured following the procedure of Gee (1970). Buoyancy was determined by dividing the swimbladder volume by the weight of the gas-free $\mathrm{fish}$ in water $\left(1.0 \mathrm{~mL} \cdot \mathrm{g}^{-1}=\right.$ neutral buoyancy). Internal pressure of swimbladder gases was measured by dividing the volume of gases released at atmospheric pressure (Pa; Appendix 1) by the swimbladder volume. Standard volume was determined by dividing the volume of gas released from the swimbladder at atmospheric pressure by the weight of the gas-free $\mathrm{fish}$ in water $\left(\mathrm{mL} \cdot \mathrm{g}^{-1}\right)$. It gave a relative measure of the amount of gas in the swimbladder, facilitating comparisons between temperatures (Appendix 1). 
Unless otherwise noted, fish were acclimated and tested in aquaria $(90 \times 45 \times 45 \mathrm{~cm})$ in either still water or current. Water velocities were created in stream tanks, based on the design of Gee and Bartnik (1969), where fish were held in an area $60 \times 40 \times 20 \mathrm{~cm}$ with stainless steel screens on the sides $\left(2.3\right.$ meshes $\left.\cdot \mathrm{cm}^{-1}\right)$ and plexiglass on the bottom. Water depth in the holding area varied between 7 and $10 \mathrm{~cm}$. Water velocity could be provided up to $35 \mathrm{~cm} \cdot \mathrm{s}^{-1}$, and its measurement was determined from the average of six measurements taken $3 \mathrm{~cm}$ from the bottom witn an Ott current meter (type C1). Temperatures were regulated either by varying the inlet temperature $\left(5-26 \pm 0.5^{\circ} \mathrm{C}\right)$ or using a thermostat $\left(26-35 \pm 0.1^{\circ} \mathrm{C}\right)$. Illumination was provided by $60 \mathrm{~W}$ light bulbs on time clocks.

Mechanism of buoyancy alteration

To determine if gas spitting and gulping are used to alter swimbladder volume, fish must be observed during the period of buoyancy adjustment. Since it is not possible to measure buoyancy without disturbing fish and perhaps altering their spitting or gulping behaviour, some other 
technique for assessing buoyancy must be used. Berezay and Gee (1978) found a strong relationship between swimming angle of attack and buoyancy in creek chub (Semotilus atromaculatus). If such a relationship exists in fathead minnows, then, the period of buoyancy adjustment could be predicted by observing the swimming angle of attack without disturbing gas regulation.

To facilitate observations of gas spitting and gulping and swimming angles, a bubble-free current tank with a current of $20 \mathrm{~cm} \cdot \mathrm{s}^{-1}$ was constructed (Fig. I). It consisted of a circular tank where fish, enclosed in a portion of the tank, were exposed to current generated by submersible pumps. observations were made from behind a blind.

Prediction of buoyancy from swimming angles. Fish were exposed to either current or still water in the bubble-free current tank, and measures of swirming angles and buoyancy were recorded to determine if buoyancy could be predicted from swimming angle. Swimming angle of attack was considered to be horizontal if a horizontal line passing through the fish's eye crossed some part of its caudal fin. If the caudal fin was below the line it was swimming 'heads-up', and vice versa. Swimming angles were observed while fish swam forward or held position in an area of current where 
.

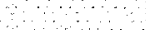

. 


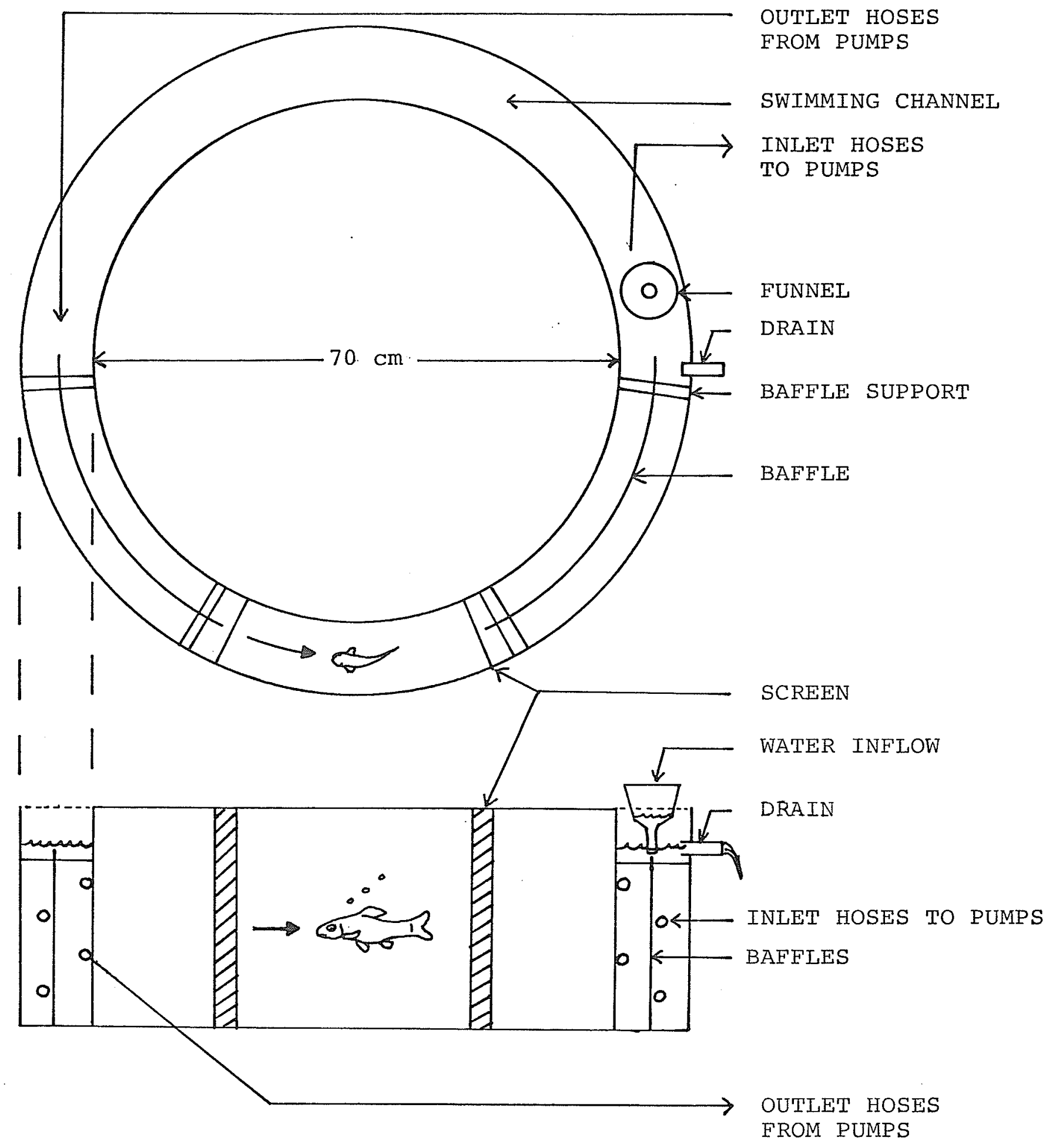


flow was as uniform as possible or in still water. Fathead minnows (40-62 mm fork length) were acclimated to $19^{\circ} \mathrm{C}$ and a 14L:10D photoperiod. Light onset (800 $\mathrm{h}$ ) and offset were gradual over 15 minutes. Groups of 42 fish were transferred to the test tank, allowed 2-4 d for acclimation, and then exposed to current. Water velocity was increased gradually to $20 \mathrm{~cm} \cdot \mathrm{s}^{-1}$ over $8 \mathrm{~min}$ beginning at $1000 \mathrm{~h}$. Measurements of buoyancy, internal pressure and standard volume (2 fish) and observations on swimming angle (5 fish every $5 \mathrm{~min} /$ for $40 \mathrm{~min}$ ) were made after $0,1,2,5,8,11$, and $23 \mathrm{~h}$ in current. Then water velocity was reduced to 0 over $8 \mathrm{~min}$ and the above procedure was repeated. These measurements were repeated four times using four different groups of fish for a total of 8 buoyancy measurements and 160 swimming angle observations at each observation time.

Buoyancy adjustment by spitting or gulping gas. To determine whether gas spitting or gulping was used to alter buoyancy, fish were observed while altering swimbladder volume in response to current or still water. Two groups of 16 fish each were acclimated and exposed to still water or current as described above. Swimming angles were used to predict the interval of buoyancy change and the frequency of spitting or gulping was noted. Gas spitting was indicated by a release of bubbles from the mouth or opercular openings. 
Gas gulping was indicated when a fish broke the meniscus and then descended, releasing bubbles from either the mouth or opercular openings. Spitting did not include gas bubbles released immediately following gulping.

\section{Buoyancy adjustment by resorption and secretion} of gas. To determine whether gas resorption or secretion was used to alter buoyancy, swimbladder gas composition and buoyancy were measured following exposure to current and still water. Fifty fathead minnows (63-84 $\mathrm{mm})$ were acclimated to $19^{\circ} \mathrm{C}$ and a 12L:12D photoperiod in still water. Beginning 2 h before light and current onset, 4 fish were sampled from still water. Current was then increased to $30 \mathrm{~cm} \cdot \mathrm{s}^{-1}$, and groups of 4 fish were sampled after 10 and $58 \mathrm{~h}$ in current. Current was shut off after $60 \mathrm{~h}$ and $4 \mathrm{fish}$ were sampled in still water after 10 and $12 \mathrm{~h}$. This procedure was repeated with a second group of $50 \mathrm{fish}$. Fish sampled after $10 \mathrm{~h}$ in still water had access to the surface but those sampled after $12 \mathrm{~h}$ had none. Fish measured after 10 or $12 \mathrm{~h}$ in still water were held in $0.5 \mathrm{I}$ containers placed in the test aquarium. Prior to withdrawing gas, the pneumatic duct and the connection between the swimbladder lobes were tied off. One sample was taken from each lobe. 
The composition of gases in the swimbladder was measured using a Carle model 8700 gas chromatograph (GC) equipped for syringe injection and respiratory gas separation (one Poropack QST 50/80 mesh and one molecular sieve 5A separation column). Samples of gas (25-100 $\mu \mathrm{L})$ withdrawn from the swimbladder were injected into the GC which separated them into $\mathrm{CO}_{2}, \mathrm{O}_{2}$ (includes $\mathrm{Ar}$ ), and $\mathrm{N}_{2}$ fractions. As each fraction passed the thermal conductivity detector in the GC it produced a peak on a recording chart whose area was proportional to the amount of the gas present. It was measured using the formula:

AREA = PEAK HEIGHT $x$ WIDTH AT HALF PEAK HEIGHT (McNair and Bonelli, 1969). The instrument'was calibrated using air and a known gas mixture of $9.59 \%$ by volume $\mathrm{C}_{2}$ ' $50.98 \% \mathrm{O}_{2}$ and Ar (inseparable), and. $39.4 \% \mathrm{~N}_{2}$.

Relative contribution of gas gulping and secretion to buoyancy increases. To determine if either gas gulping or gas secretion predominate as the method of buoyancy increase, the gulping behaviour and rate of buoyancy increase were observed in fish whose buoyancy had been lowered to about $0.5 \mathrm{~mL} \cdot \mathrm{g}^{-1}$. Eight fish (49-83 mm), acclimated to $19^{\circ} \mathrm{C}$ and a $12 \mathrm{~L}: 12 \mathrm{D}$ photoperiod in still water, were individually subjected to ambient pressures of about $50 \mathrm{kPa}(1 \mathrm{~atm}=101.3 \mathrm{kPa})$. Pressure 
reduction was gradual and the number of gas bubbles released by the fish was noted. Once the fish was neutrally buoyant at this reduced pressure, pressure was returned to atmospheric and the negatively buoyant fish was transferred to an aquarium balance system (Gee and Graham, 1978) where its weight in water was recorded at regular intervals and the time of gulping was noted until no further changes occurred. The fish was then killed and its weight in water without the swimbladder was measured, making it possible to relate changes in the weight in water to actual increases in swimbladder volume and to identify the relative contribution of gulping and spitting to this increase.

Ability to Maintain a Minimum Buoyancy

Short term buoyancy maintenance. To determine if a diel rhythm in buoyancy fluctuation existed, buoyancy measurements were made every $4 \mathrm{~h}$ for $48 \mathrm{~h}$ in still water and in current. Fish (4I-66 mm) collected in October, 1978 were held at $11^{\circ} \mathrm{C}$ on a 12L:12D photoperiod for 30 days. During November and December, they were acclimated to $21^{\circ} \mathrm{C}$, one group of 125 fish in still water and another in $20 \mathrm{~cm} \cdot \mathrm{s}^{-1}$ current. This 
photoperiod was maintained in a quiet room until sampling in late January. Groups of $8 \mathrm{fish}$ were examined from both still water and current after 50 days of acclimation to their test conditions. Red lamps (40W) were used for illumination during night sampling with no obvious effect on fish behaviour. The fish were starved during the 48 h period.

Long term effects of water velocity. To determine the effect of water velocity on ability to maintain a minimum buoyancy in current fish $(40-68 \mathrm{~mm})$ collected in November, 1977 were divided into two batches, acclimated to either 21 or $30^{\circ} \mathrm{C}$, and exposed to water velocities of either 10 , 20 , or $30 \mathrm{~cm} \cdot \mathrm{s}^{-1}$. Velocities in stream tanks were gradually increased to the desired level over $6 \mathrm{~h}$ following introduction of fish. Testing occurred between February and May, 1978, when 8 fish were examined from each treatment after $0,2,4$, $7,10,18,26,34$, and $42 \mathrm{~d}$ in current. Fish were fed following sampling.

Long term effects of water temperature. The effect of water temperature was measured at a velocity of $20 \mathrm{~cm} \cdot \mathrm{s}^{-1}$ where fish were exposed to temperatures of $5,11,21,26$, and $30^{\circ} \mathrm{C}$. Sampling was conducted as above. 
Effects of stress from temperature and velocity.

To determine the effects of stress from high water temperature and velocity on the ability to maintain a minimum buoyancy in current, fish were exposed to four treatments :

1) constant temperature of $25^{\circ} \mathrm{C}$ and water velocity of $12.5 \mathrm{~cm} \cdot \mathrm{s}^{=1}$,

2) increase in temperature from 25 to $31^{\circ} \mathrm{C}$ at $1^{\circ} \mathrm{C} \cdot \mathrm{d}^{-1}$ and then from 31 to $34.5^{\circ} \mathrm{C}$ at $0.5^{\circ} \mathrm{C} \cdot \mathrm{d}^{-1}$ with a constant water velocity of $12.5 \mathrm{~cm} \cdot \mathrm{s}^{-1}$,

3) increase in water velocity from 12.5 to $27.5 \mathrm{~cm} \cdot \mathrm{s}^{-1}$ at $5 \mathrm{~cm} \cdot \mathrm{s}^{-1} \cdot 48 \mathrm{~h}^{-1}$ and then from 27.5 to $35 \mathrm{~cm} \cdot \mathrm{s}^{-1} \cdot 48 \mathrm{~h}^{-1}$ with temperature held constant at $25^{\circ} \mathrm{C}$,

4) increase in temperature and velocity as described above, except temperature was increased to $35^{\circ} \mathrm{C}$.

Four groups of fish (39-66 mm), collected in October 1978, were acclimated to $25^{\circ} \mathrm{C}$ in stream tanks and tested between 26 November and 10 December 1978. Treatments began following a 10 day acclimation to a $12.5 \mathrm{~cm} \cdot \mathrm{s}^{-1}$ water current and 8 fish per treatment were sampled daily. Temperatures and water velocities were adjusted and fish were fed following the daily sampling period. 
Statistical Analysis

Regression analyses, lack of fit tests on the regressions, and two-way analyses of variance tests were done on an IBM/370 computer, using APL statistical programme 5796-PHW. All fish were chosen randomly for measurement and observation. Unless otherwise noted, analyses were done on individual measurements and not on the mean values for each treatment. All differences were considered significant if the probability of error was less than $5 \%(P<0.05)$. Significance in the appendices is denoted by an asterisk (*) and the vertical lines from the means, on some of the graphs, represent the $95 \%$ confidence interval (CI). Note: In the appendices, $F$ values calculated from the mean sum of squares (mss) often do not agree with the $F$ values Iisted. This occurs because each of the mss values was rounded off from 16 digits before placement in the ANOVA tables. F values in the tables were calculated using all 16 digits of the mss and are correct. 


\section{RESULTS}

Mechanism of Buoyancy Alteration.

Prediction of buoyancy from swimming angle. When transferred from still water to current, fish decreased their buoyancy from 0.720 to $0.596 \mathrm{~mL} \cdot \mathrm{g}^{-1}$ over $12 \mathrm{~h}$ (Fig. 2). On initial contact with current most fish adopted a heads-down angle of attack which gradually shifted to horizontal as buoyancy adjustment was completed. On exposure to still water buoyancy increased from 0.653 to $0.852 \mathrm{~mL} \cdot \mathrm{g}^{-1}$ over $12 \mathrm{~h}(\mathrm{Fig} .2)$. When still water was encountered most fish initially adopted a heads-up swimming angle of attack which gradually became horizontal as buoyancy adjustment was completed. The regressions of mean buoyancy on percent swimming horizontally during buoyancy adjustment downwards (in current) and upwards (in still water) were significant (Fig. 3, Appendix 2), indicating that swimming angle is a good predictor of buoyancy

Buoyancy adjustment by spitting and gulping gas. Fish seldom spit gas during the period of buoyancy adjustment. Spitting bubbles occurred in still water and in current just after light onset and during the first hour of exposure to 
Figure 2. Mean buoyancy (solid circles; $\mathrm{n}=8$ ) and the percent of fish swimming horizontally (open circles) plotted for the first $12 \mathrm{~h}$ of adjustment to either current or still water. 


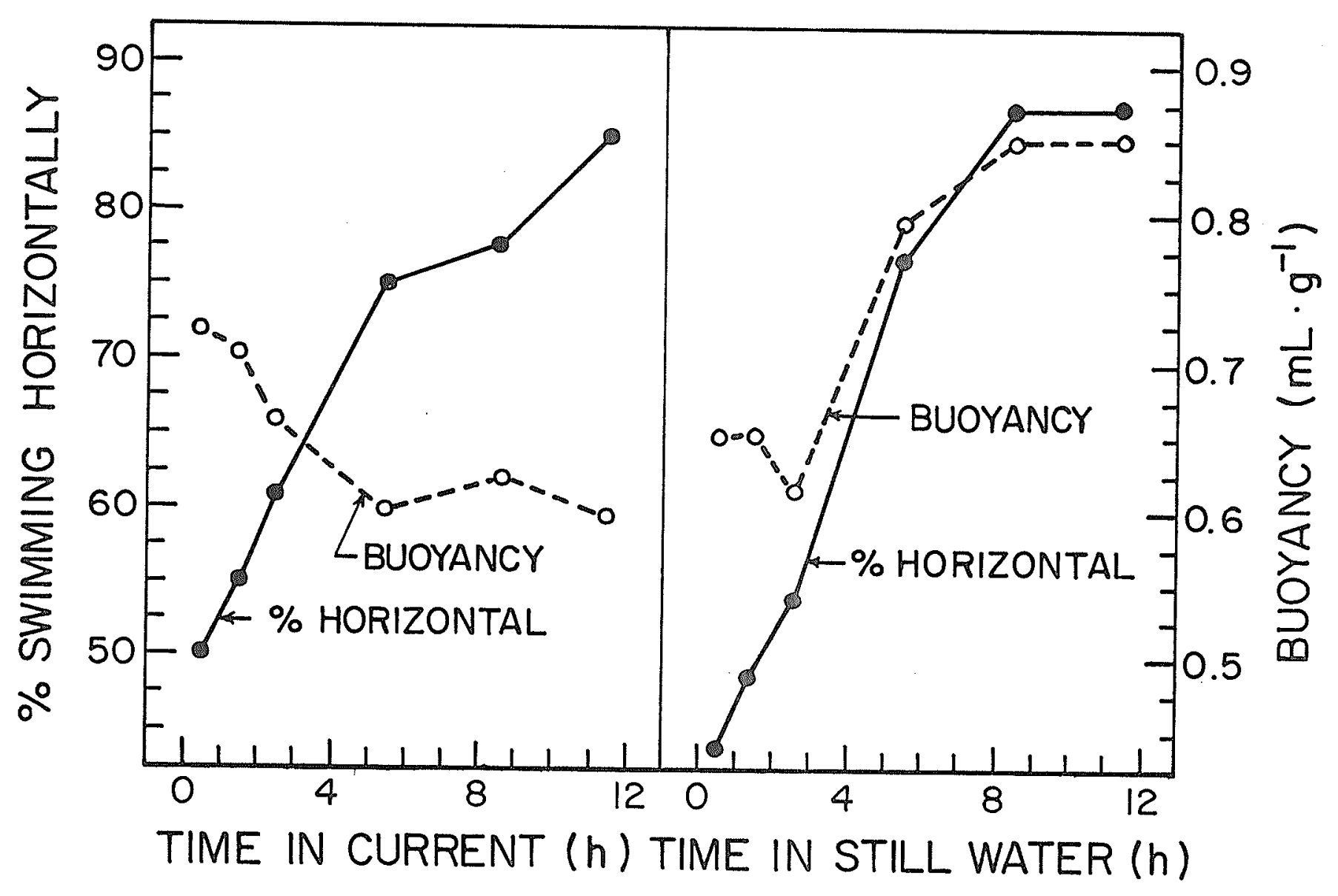


Figure 3. Regression analysis of mean buoyancy $(n=8)$ on percent of the fish swimming horizontally during the first $12 \mathrm{~h}$ of adjustment to current (solid circles) and still water (open circles). 


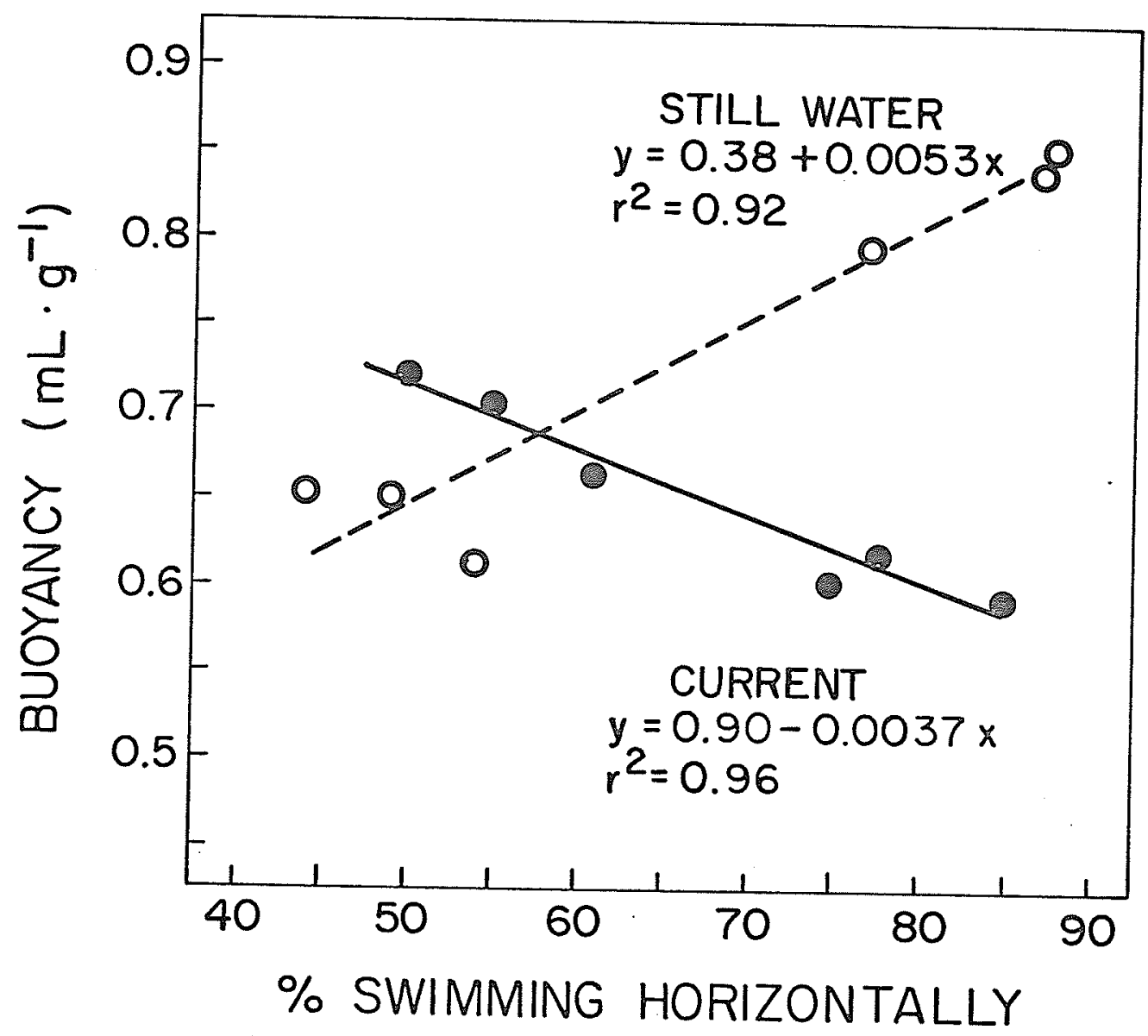


current (Fig. 4). Fish gulped air at the surface in both current and still water but the frequency was greatest during the initial $6 \mathrm{~h}$ of exposure to still water (Fig. 4). Apart from the hour following light onset, there was no spitting or gulping of gas when buoyancy was not being adjusted (i.e., when 95\% of the fish were swimming horizontally).

Buoyancy adjustment by resorption and secretion of gas. When fathead minnows exposed to $30 \mathrm{~cm} \cdot \mathrm{s}^{-1}$ current reduced their buoyancy, they altered the composition of gases in their swimbladders by decreasing the amounts of $\mathrm{CO}_{2}$ and $\mathrm{O}_{2}$ relative to the amount of $\mathrm{N}_{2}$ (Fig. 5). This was apparent in current after $12 \mathrm{~h}$ and the composition remained unchanged after $60 \mathrm{~h}$. When they increased buoyancy after the current stopped, the reverse occurred. Fish with access to the surface returned their $0_{2}$ and $\mathrm{N}_{2}$ levels to near the initial still water values but their $\mathrm{CO}_{2}$ concentration was higher. Fish without access had similar $\mathrm{C}_{2}$ levels to those with access but $\mathrm{O}_{2}$ levels were higher and $\mathrm{N}_{2}$ levels were lower. The gas composition in anterior and posterior lobes of the swimbladder was similar. 
Figure 4. Frequency of spitting bubbles and surface gulping by fish when exposed to current for $24 \mathrm{~h}$ (buoyancy reduced) and then still water for $24 \mathrm{~h}$ (buoyancy increased). Buoyancy adjustment was complete when $95 \%$ of the fish swam horizontally. Spitting and gulping occurring outside the period of buoyancy adjustment are indicated by solid bars. 


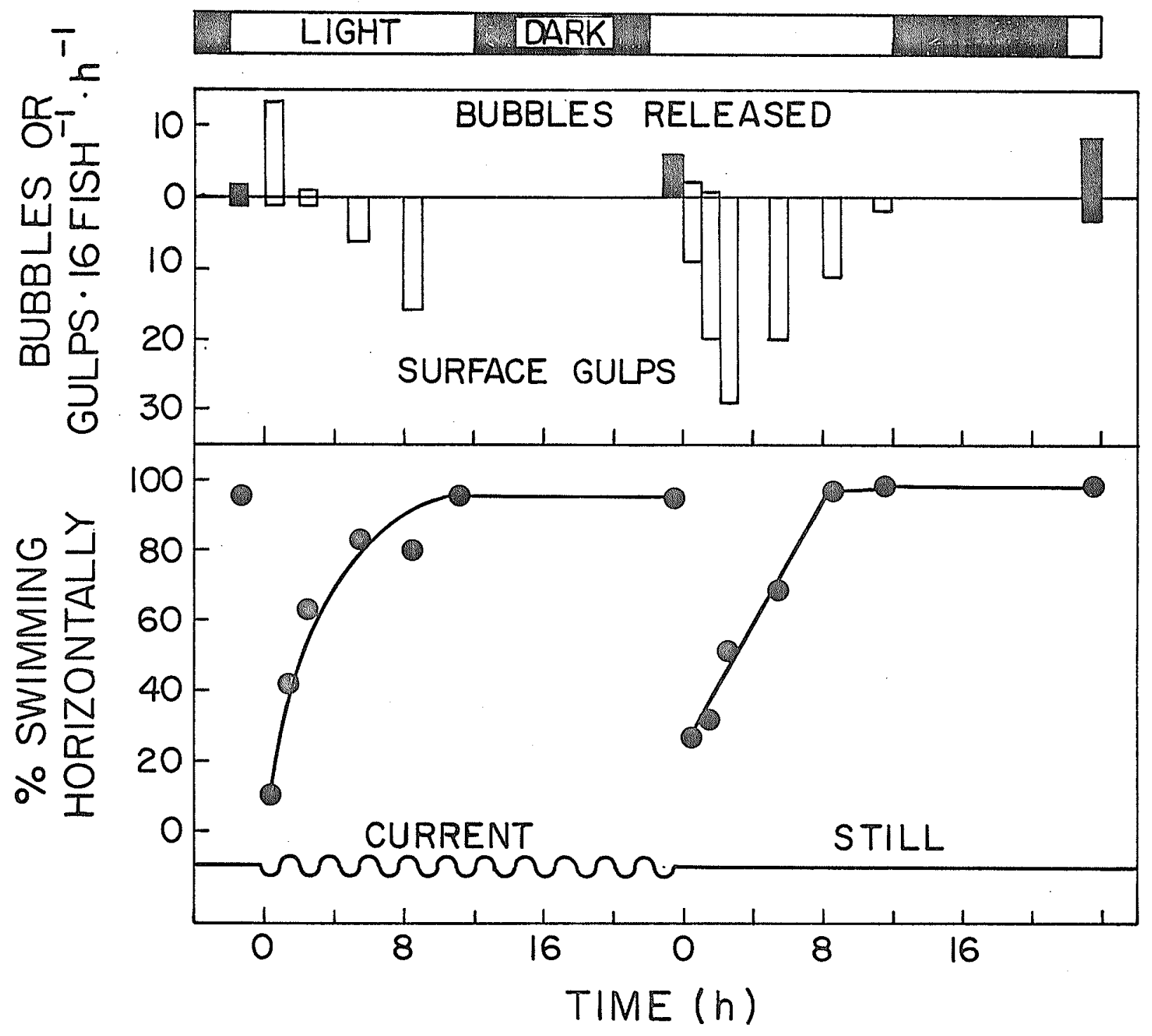


Figure 5. Percent of the swimbladder gas volume consisting of $\mathrm{N}_{2}, \mathrm{O}_{2}$, and $\mathrm{CO}_{2}$ and buoyancy in current and still water, with access to the surface (solid circles) and without access (squares). Vertical Iines are 95\% confidence intervals for the means. 


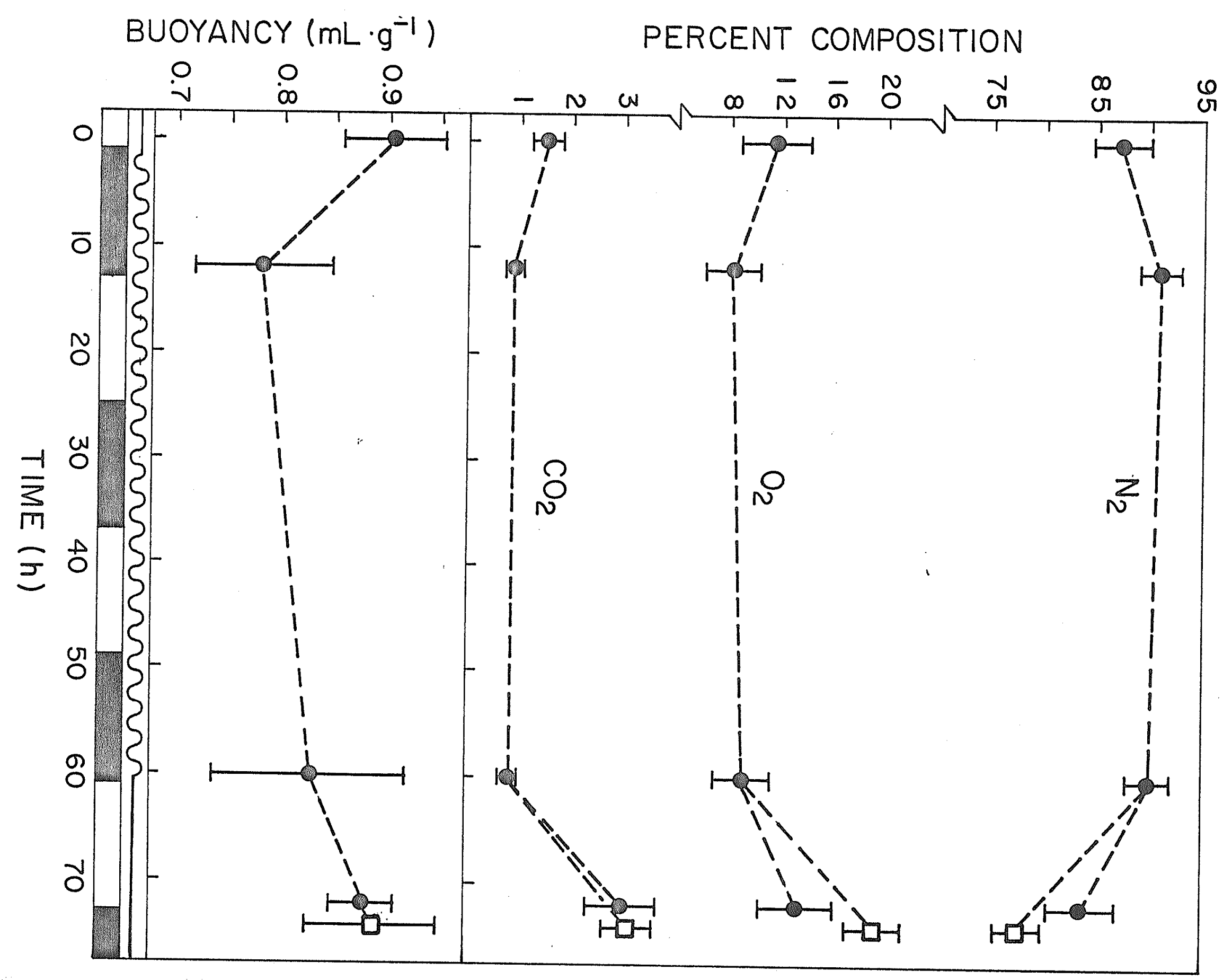


Relative contributions of gas gulping and secretion to buoyancy increases. Fish which had their buoyancy reduced by about 50\% were variable in the rate of return to neutral buoyancy (Table 1). The quickest did so mainly by gulping air into the swimbladder, while slowly adjusting fish relied more on gas secretion (Fig. 6). Small fish were able to increase their buoyancy by secretion significantly faster than large fish, but the proportion of the overall adjustment due to secretion was independent of size. The rate of buoyancy adjustment by gas secretion was related to the length of the fish by the equation, $y=0.0700-$ $0.0005 \times\left(r^{2}=0.76\right.$; Appendix 3). The volume of air forced into the swimbladder during an average gulp was significantly larger in large fish $(72-83 \mathrm{~mm} ; \overline{\mathrm{x}}=20 \mu \mathrm{L})$ than in small fish $(49-67 \mathrm{~mm} ; \overline{\mathrm{x}}=11 \mu \mathrm{L})$ but the volume of gas released by spitting gas bubbles during buoyancy decrease was independent of length.

\section{Ability to Maintain Buoyancy}

Short term buoyancy maintenance in still water and current. Buoyancy was maintained over a narrower range in still water than in current during the $48 \mathrm{~h}$ test period (Fig. 7). In still water, buoyancy was significantly 
Tabie 1. Contributions of gas gulping and secretion to buoyancy increases during the return to neutral buoyancy in still water.

\begin{tabular}{|c|c|c|c|c|c|c|c|c|c|}
\hline \multirow{3}{*}{$\begin{array}{l}\text { Lengtin } \\
(\mathrm{rm}) \\
\end{array}$} & \multirow{2}{*}{\multicolumn{2}{|c|}{ Buoyancy $\left(\mathrm{mL} \cdot \mathrm{g}^{-1}\right)$}} & \multirow{3}{*}{$\begin{array}{l}\text { Adjustment } \\
\text { Time (h) }\end{array}$} & \multicolumn{4}{|c|}{ Method of Buoyancy Change } & \multirow{2}{*}{\multicolumn{2}{|c|}{ Mean Volume $\mu \mathrm{L}$}} \\
\hline & & & & \multicolumn{2}{|c|}{ Gulping } & \multicolumn{2}{|c|}{ Secretion** } & & \\
\hline & Initial & FinaI & & $\mathrm{mL} \cdot \mathrm{g}^{-1} \cdot \mathrm{h}^{-1}$ & $\%$ & $\mathrm{~mL} \cdot \mathrm{g}^{-1} \cdot \mathrm{h}^{-1}$ & $\%$ & Gulp & Spit \\
\hline 83 & 0.35 & 0.98 & 7.0 & 0.062 & 69 & 0.028 & 31 & 17 & 4 \\
\hline 81 & 0.36 & 0.98 & 5.0 & 0.091 & 77 & 0.029 & 23 & 17 & 7 \\
\hline 78 & 0.50 & 0.98 & 4.5 & 0.084 & 78 & 0.023 & 22 & 20 & 2 \\
\hline 72 & 0.54 & 0.99 & 1.0 & 0.418 & 93 & 0.032 & 7 & 26 & 3 \\
\hline 67 & 0.75 & 0.99 & 2.0 & 0.077 & 64 & 0.043 & 36 & 9 & 1 \\
\hline 62 & 0.44 & 0.94 & 10.5 & 0.011 & 23 & 0.037 & 77 & 5 & 3 \\
\hline 49 & 0.53 & 0.95 & 3.5 & 0.076 & 63 & 0.044 & 37 & 3 & 1.5 \\
\hline 49 & 0.66 & 1.00 & 1.5 & 0.187 & 81 & 0.043 & 19 & 4 & 1 \\
\hline
\end{tabular}

** Mean secretion rates were: $\begin{aligned} 49-67 \mathrm{~mm} & =0.042 \mathrm{~mL} \cdot \mathrm{g}^{-1} \cdot \mathrm{h}^{-1} \\ & 72-83 \mathrm{~mm}=0.028 \mathrm{~mL} \cdot \mathrm{g}^{-1} \cdot \mathrm{h}^{-1}\end{aligned}$ 
Figure 6. Progression of buoyancy alteration in a fathead minnow using air gulping (indicated by an arrow) and gas secretion to increase buoyancy. Solid lines indicate continuous observations, dotted lines interpolations between half-hourly observations. 


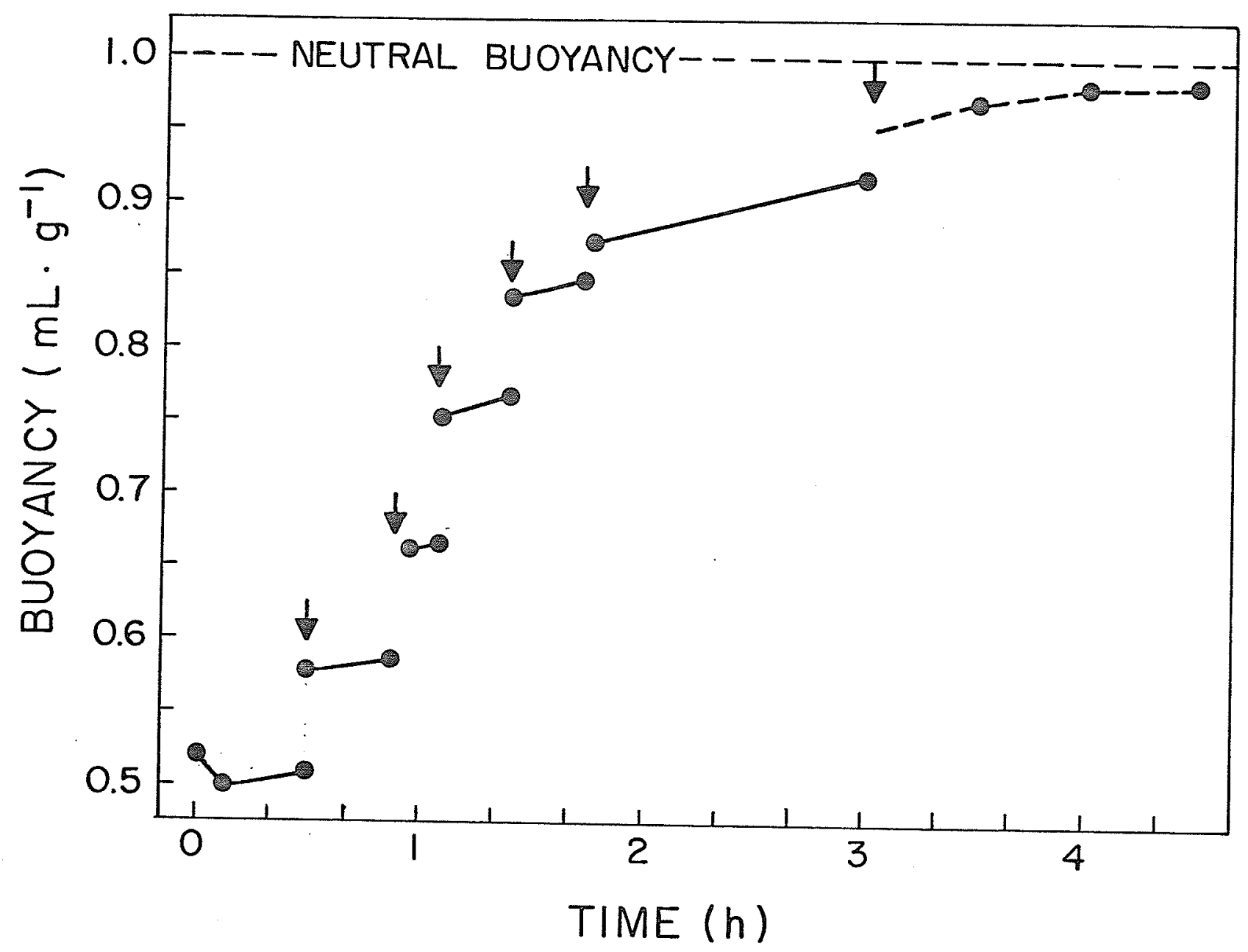


Figure 7. Buoyancy (solid circles), standard volume (open circles), and internal pressure (crosses) measured over $48 \mathrm{~h}$ in still water and current. Points are means of 8 fish. 


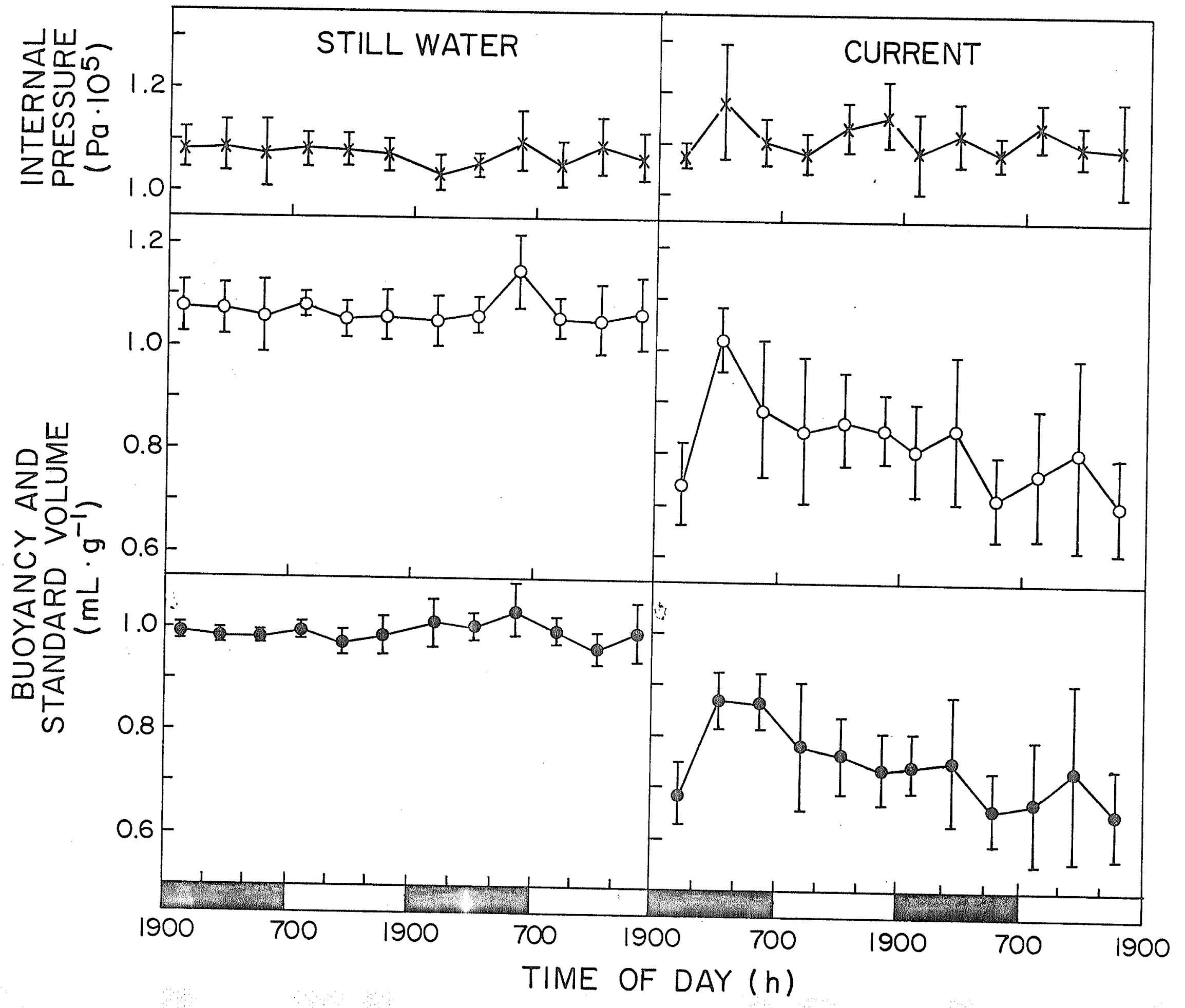


higher during the second dark period than during the rest of the experiment while internal pressure and standard volume remained constant (Appendix 4). In current, buoyancy and standard volume were greater on day 1 than on day 2 while internal pressure remained constant. No diel rhythm was apparent in buoyancy, eliminating the need to sample at a set time.

\section{Long term effects of water temperature and velocity on} buoyancy maintenance. At $21^{\circ} \mathrm{C}$, a two-way analysis of variance on effects of water velocity on buoyancy over time in current $(2-42$ d) showed that the main effect of velocity was not significant, that significant differences occurred over time, and that there was no interaction between the effects of water velocity and time in current (Appendix 5). Following the initial decline between day 0 and 2, buoyancy decreased slowly until day 18 after which there was little change (Fig. 8). Fish maintained similar buoyancies at all velocities.

At $30^{\circ} \mathrm{C}$, effects of water velocity were significant but buoyancy did not vary significantly over time (day 2-48). The interaction between these factors was significant (Appendix 5). Within each water velocity there was considerable variation in buoyancy which did not stabilize until after day 10, after which fish in faster velocities maintained lower buoyancies (Figs. 8 and 9). 
Figure 8. Mean buoyancies $(n=8)$ between 0 and 42 days in 10,20 and $30 \mathrm{~cm} \cdot \mathrm{s}^{-1}$ current at either $21^{\circ} \mathrm{C}$ or $30^{\circ} \mathrm{C}$. 


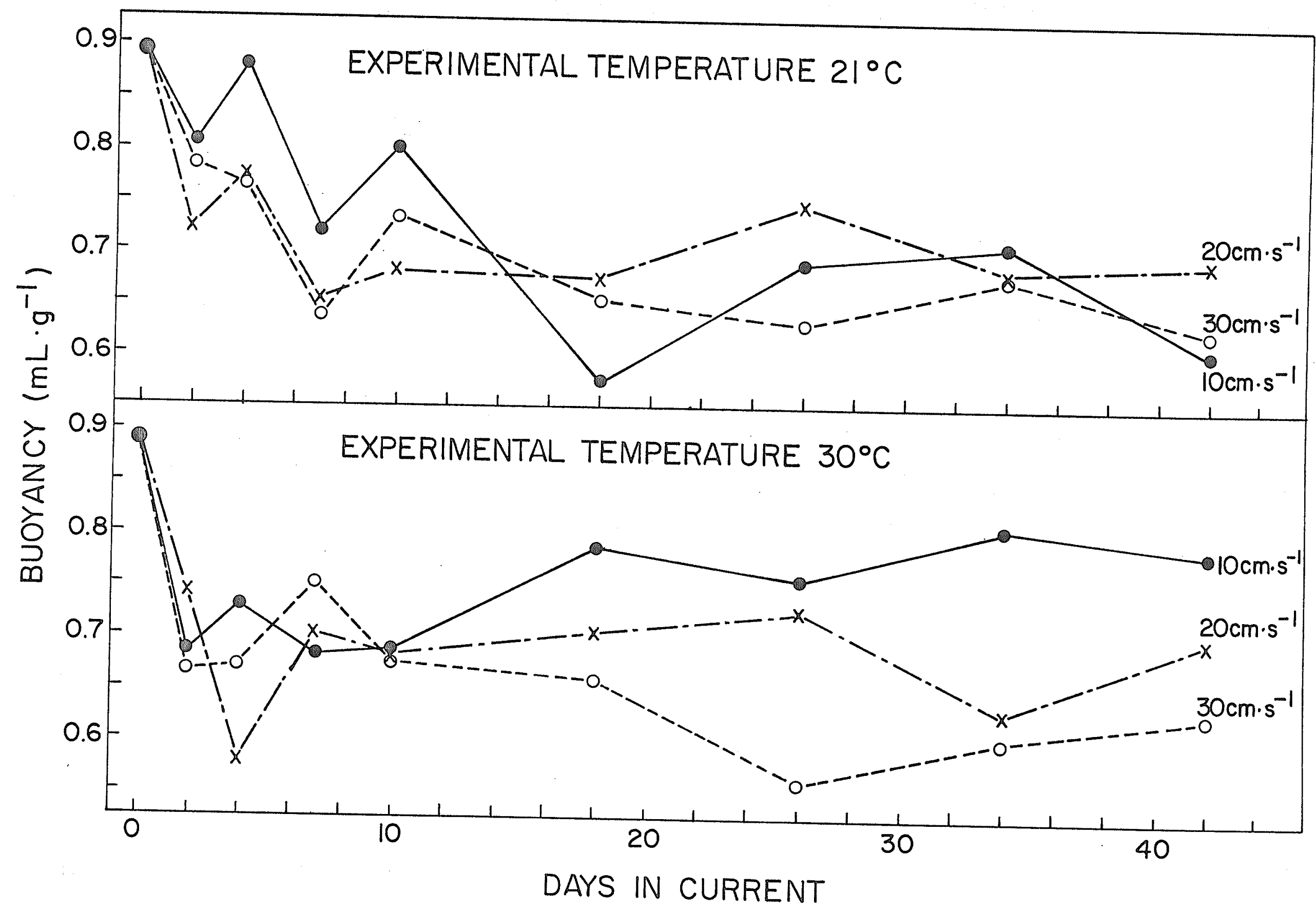


Figure 9. Effects of water velocity on mean $(n=40)$ buoyancy (solid circles), standard volume (open circles) and internal pressure (crosses) at $30^{\circ} \mathrm{C}$, between 10 and 42 days in current. Solid lines are significant. 


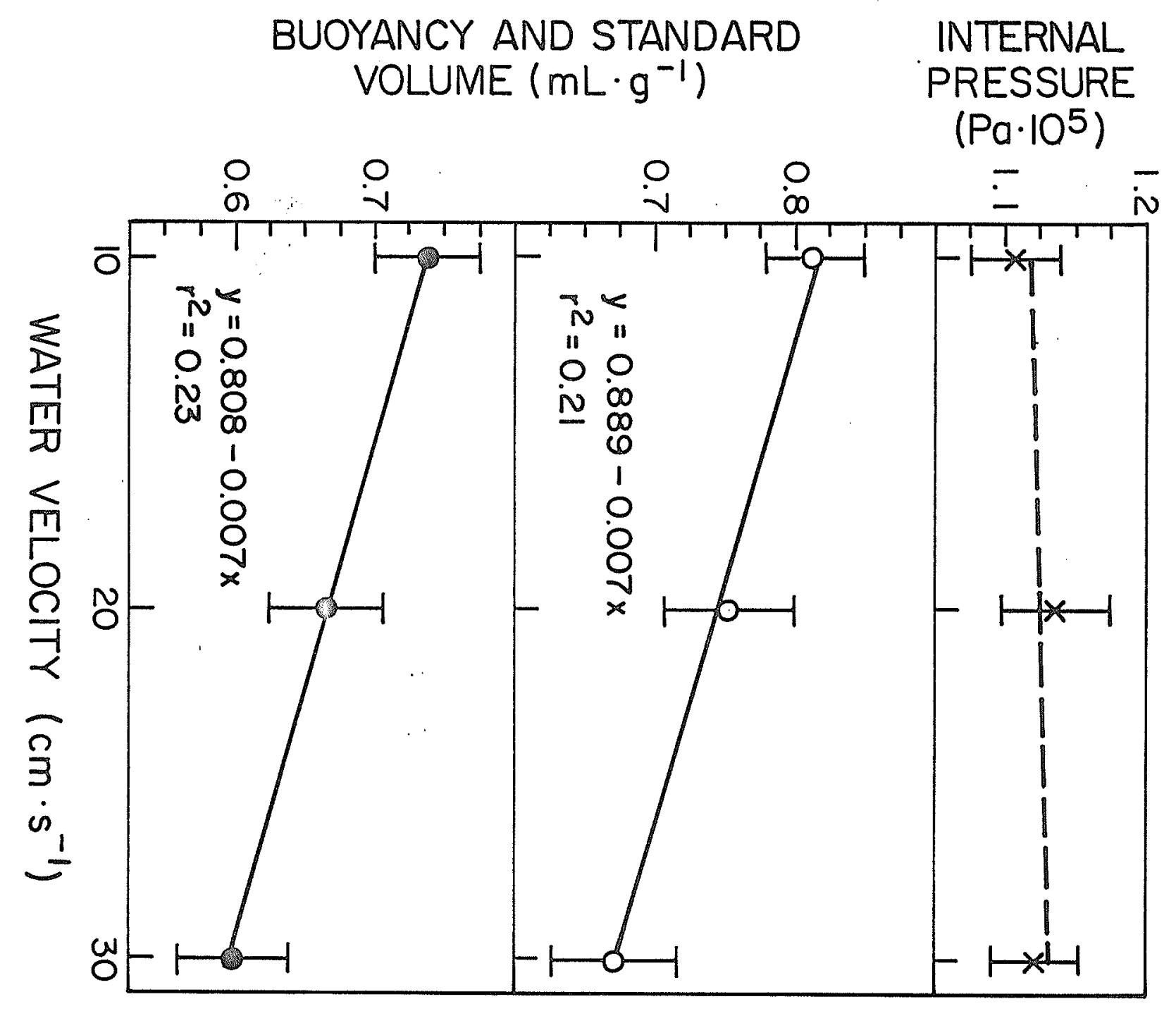


Buoyancy changes at each temperature resulted primarily from changes in standard volume of the swimbladder (Appendix 5, Fig. 9). Because there were interactions between effects of water velocity and time, neither buoyancy, internal pressure, nor standard volume could be lumped for overall regression analyses.

In $20 \mathrm{~cm} \cdot \mathrm{s}^{-1}$ current, the main effects of both water temperature and time in current on buoyancy were significant (Appendix 5). These effects were complicated by a just significant $(0.04<\mathrm{P}<0.05)$ time-temperature interaction which, for the sake of comparison, was ignored. Following the initial decline between day 0 and day 2, buoyancy remained variable but was maintained at a relatively constant level for each temperature (Fig. 10). Buoyancy changes over time and at each temperature were determined by internal pressure and standard volume (Figs. 11 and 12 ).

In temperature and velocity experiments, internal pressure was generally highest and most variable during the first 10 days in current (Appendix 5).

\section{Effects of stress from temperature and water velocity} on buoyancy maintenance. Control fish held at $25^{\circ} \mathrm{C}$ in $12.5 \mathrm{~cm} \cdot \mathrm{s}^{-1}$ current gradually reduced both buoyancy and standard volume significantly but did not change their internal pressure during the experiment (regression analyses: Fig. 13, Appendix 6). Lack of fit tests on the regressions for buoyancy and standard volume were significant. 
Figure 10. Mean buoyancies $(n=8)$ between 0 and 42 days in $20 \mathrm{~cm} \cdot \mathrm{s}^{-1}$ current at $5^{\circ} \mathrm{C}$ (solid circles), $11^{\circ} \mathrm{C}$ (solid triangles), $21^{\circ} \mathrm{C}$ (crosses), $26^{\circ} \mathrm{C}$ (open triangles), and $30^{\circ} \mathrm{C}$ (open circles). 


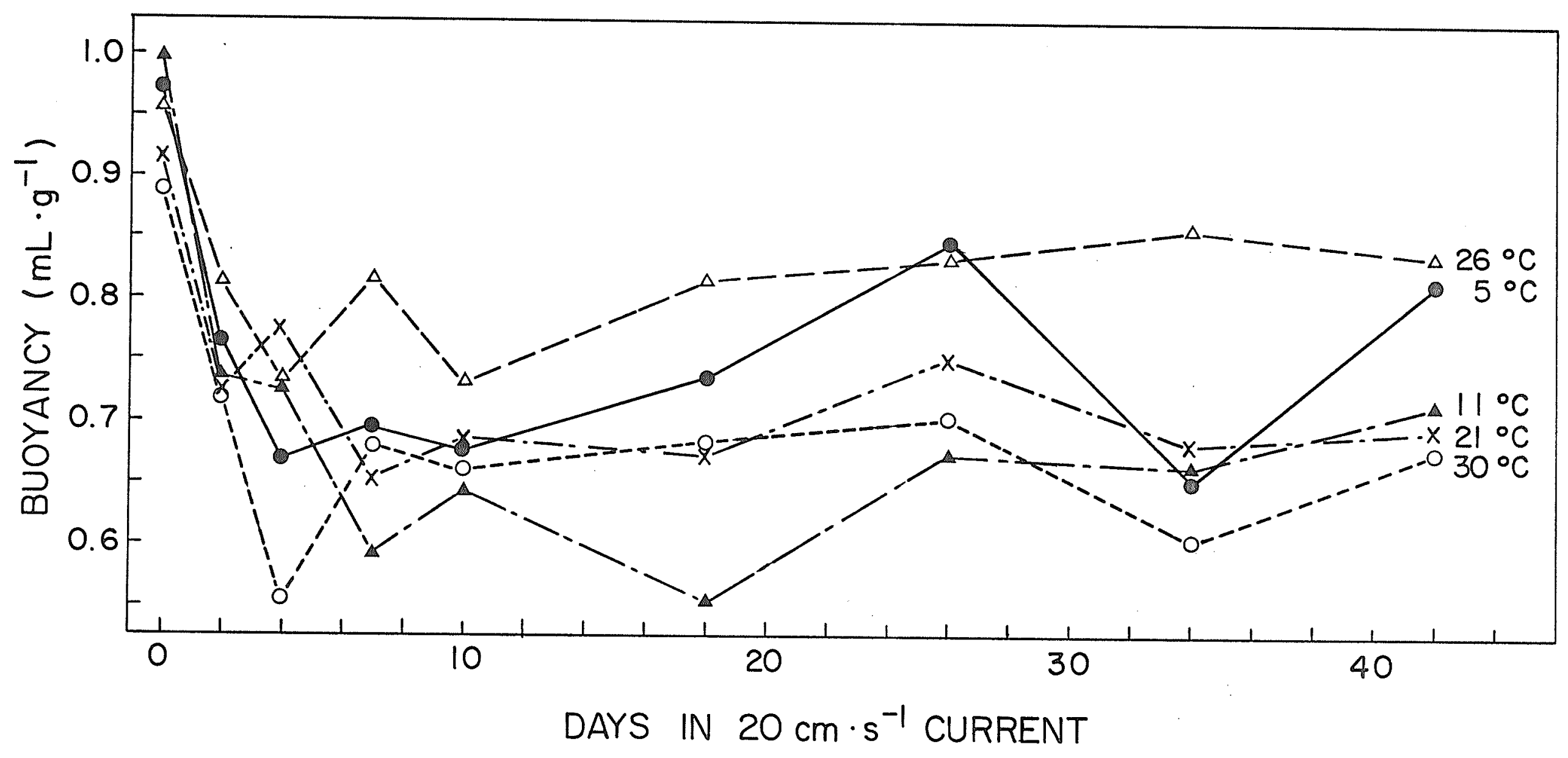


Figure 11. Effect of time in current on mean $(n=40)$ buoyancy (solid circles), standard volume (open circles), and internal pressure (crosses). Measurements are lumped for all temperatures. 


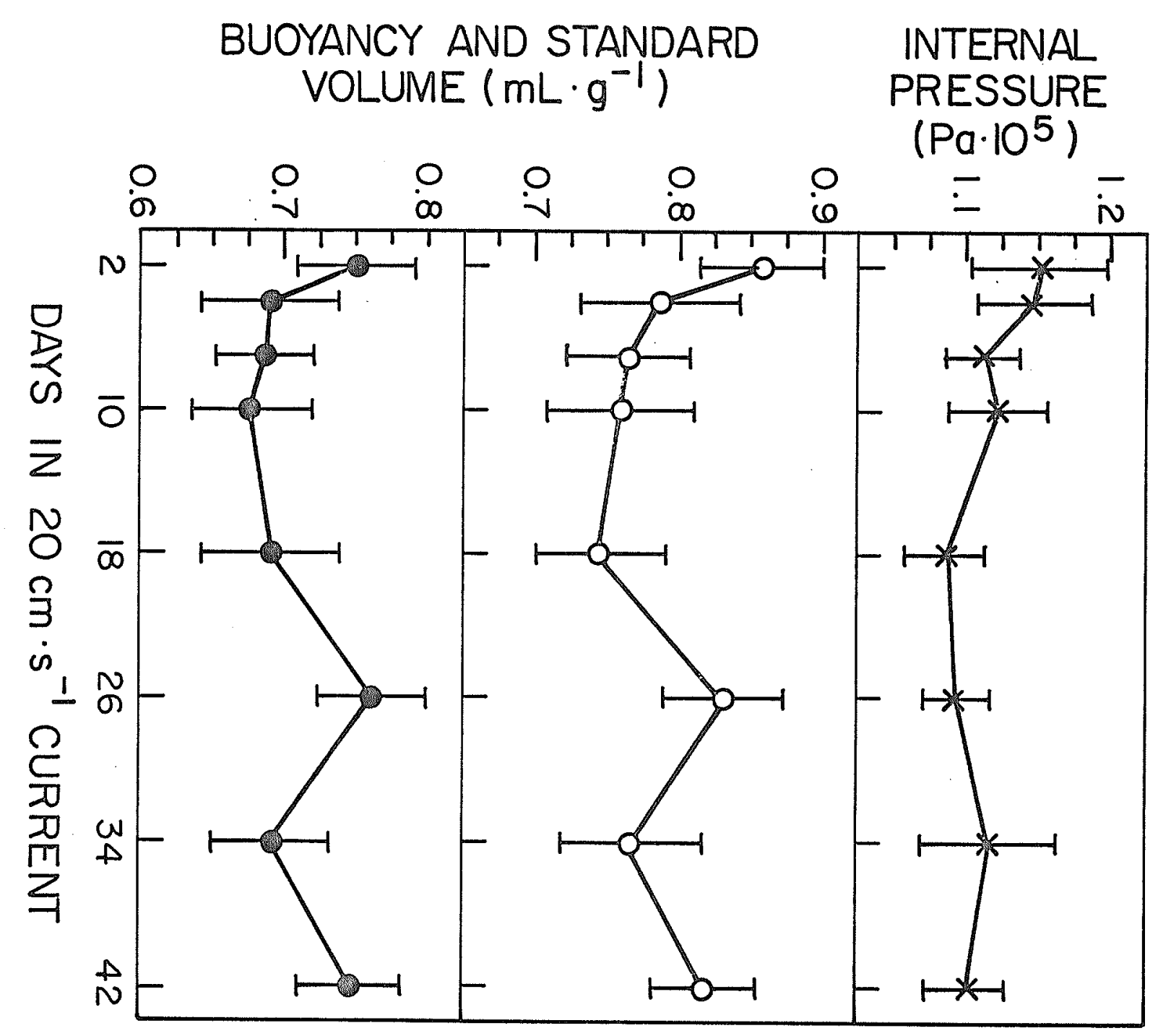


31

Figure 12. Effects of temperature on mean $(n=64)$ buoyancy (solid circles), standard volume (open circles), and internal pressure (crosses). Measurements are lumped over time $(2-42$ d) . 


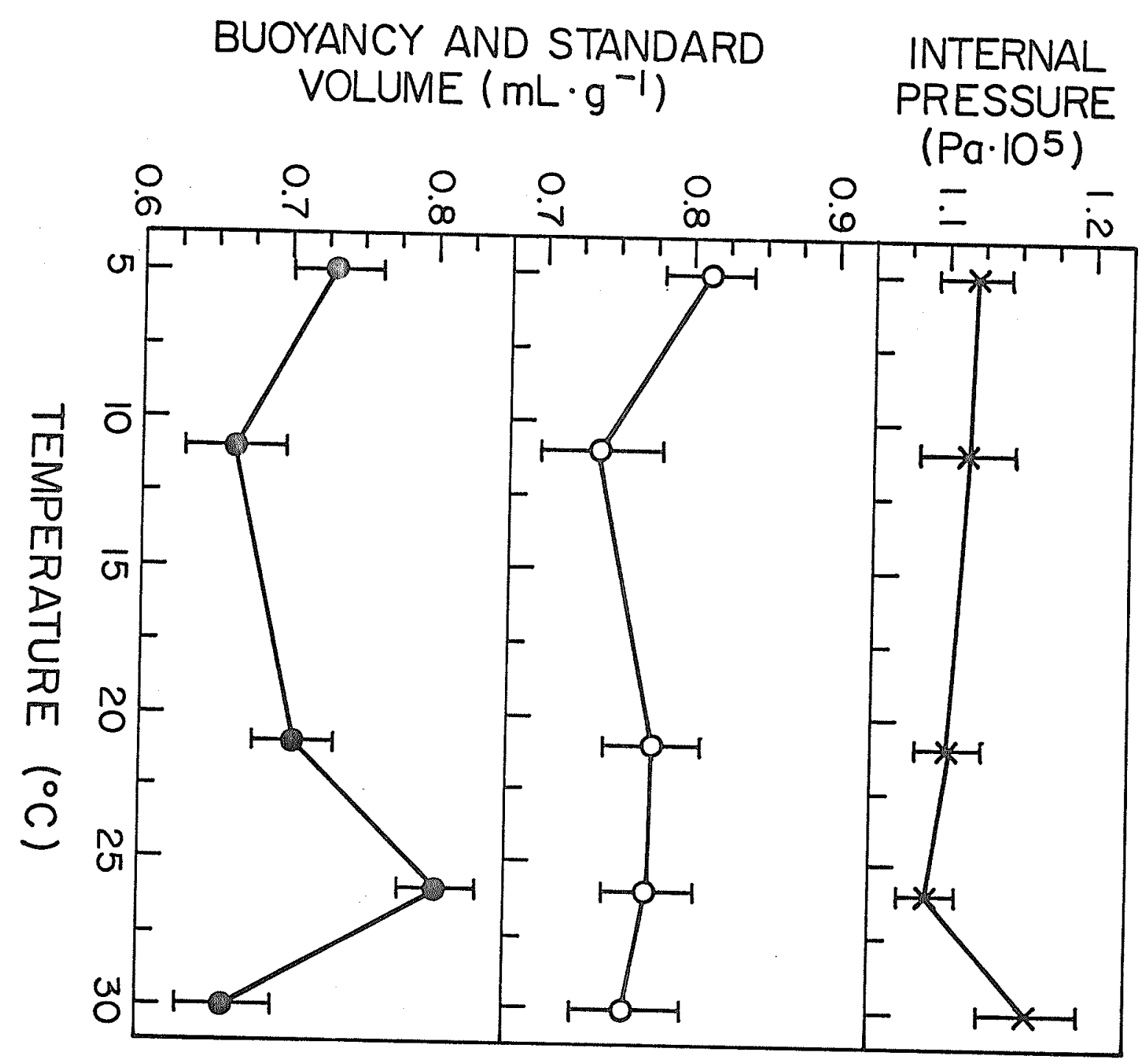


Figure 13. Regressions against time for buoyancy (solid circles), standard volume (open circles), and internal pressure (crosses) when water temperature and velocity are held constant. Solid lines are significant and points are included for the means $(n=8)$. 


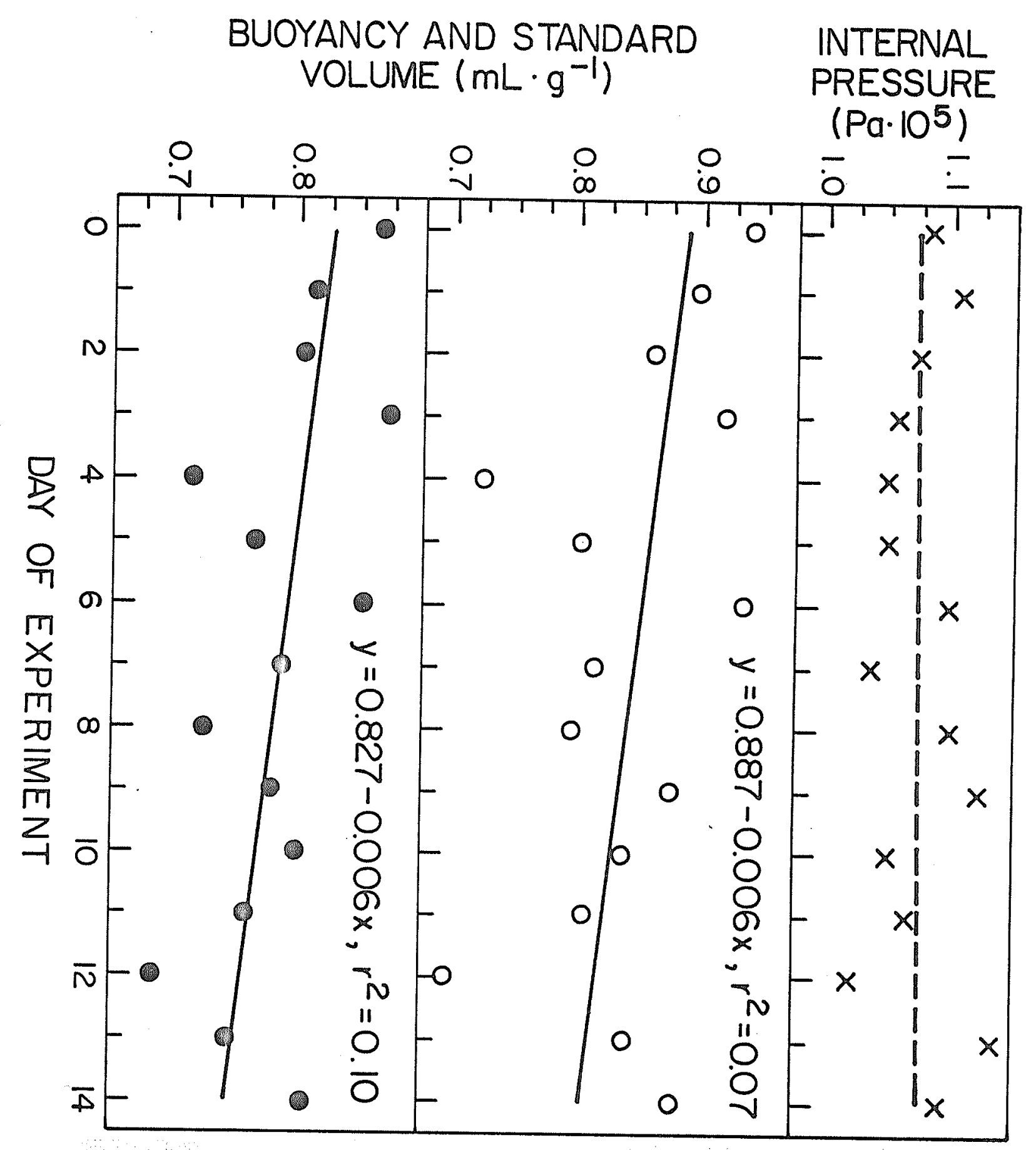


In $12.5 \mathrm{~cm} \cdot \mathrm{s}^{-1}$ current, increasing the water temperature resulted in a significant linear increase in the internal pressure of the swimbladder over time (regression analyses: Fig. 14, Appendix 6).

At $25^{\circ} \mathrm{C}$, increasing the water velocity prompted significant decreases in buoyancy and standard volume and a significant increase in the internal pressure over time (regression analyses: Fig. 15, Appendix 6). Lack of fit tests on the buoyancy and internal pressure regressions were significant.

Increasing temperature and velocity prompted both internal pressure and standard volume to increase significantly (Fig. 16, Appendix 6). Both regressions had significant lack of fit tests.

Significant lack of fit tests suggested that many of the relationships were non-linear and might perhaps follow some more complex trend. However, in no case could a more complex trend be found to fit and the linear relationships remain for illustration. Poor fits of the regression lines to the data resulted from a high degree of variability in the measurements. Both buoyancy and standard volume means had high but constant variabilities. The variance of internal pressure measurements was not constant in conditions of increasing water temperature and/or velocity. When internal pressure was high so was variance (Fig. 17, Appendix 6). Logarithmic transformations were performed on the internal pressures to correct for this increasing variance. Because they had little effect on the significance, $r^{2}$, and fit of the Iines, untransformed internal pressures were used. 
Figure 14. Regressions against time for buoyancy (solid circles), standard volume (open circles), and internal pressure (crosses) when water temperature is increasing and velocity is constant. Solid lines are significant and points are included for the means $(n=8)$. 


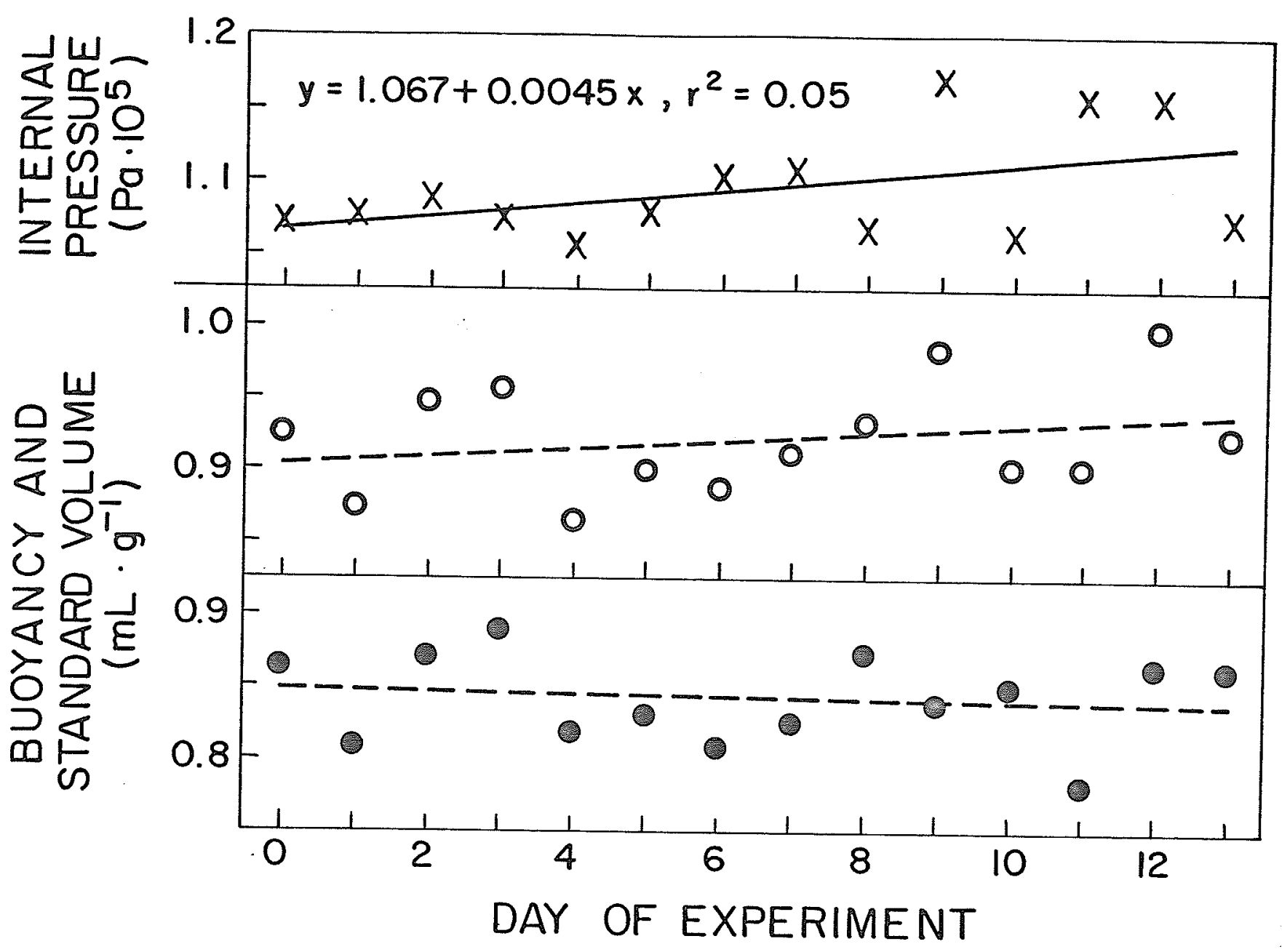

\begin{tabular}{|c|c|c|c|c|c|c|c|c|c|c|c|c|c|c|}
\hline $\begin{array}{c}\text { TEMPERATURE } \\
\left({ }^{\circ} \mathrm{C}\right)\end{array}$ & 25 & 26 & 27 & 28 & 29 & 30 & 31 & 31.5 & 32 & 32.5 & 33 & 33.5 & 34 & 34.5 \\
\hline
\end{tabular} 
Figure 15. Regressions against time for buoyancy (solid circles), standard volume (open circles), and internal pressure (crosses) when water temperature is constant and velocity is increasing. Solid lines are significant and points are included for the means $(n=8)$. 
Figure 16. Regressions against time for buoyancy (solid circles), standard volume (open circles), and internal pressure (crosses), when both water temperature and velocity are increasing. Solid lines are significant and points are included for the means $(n=8)$. 


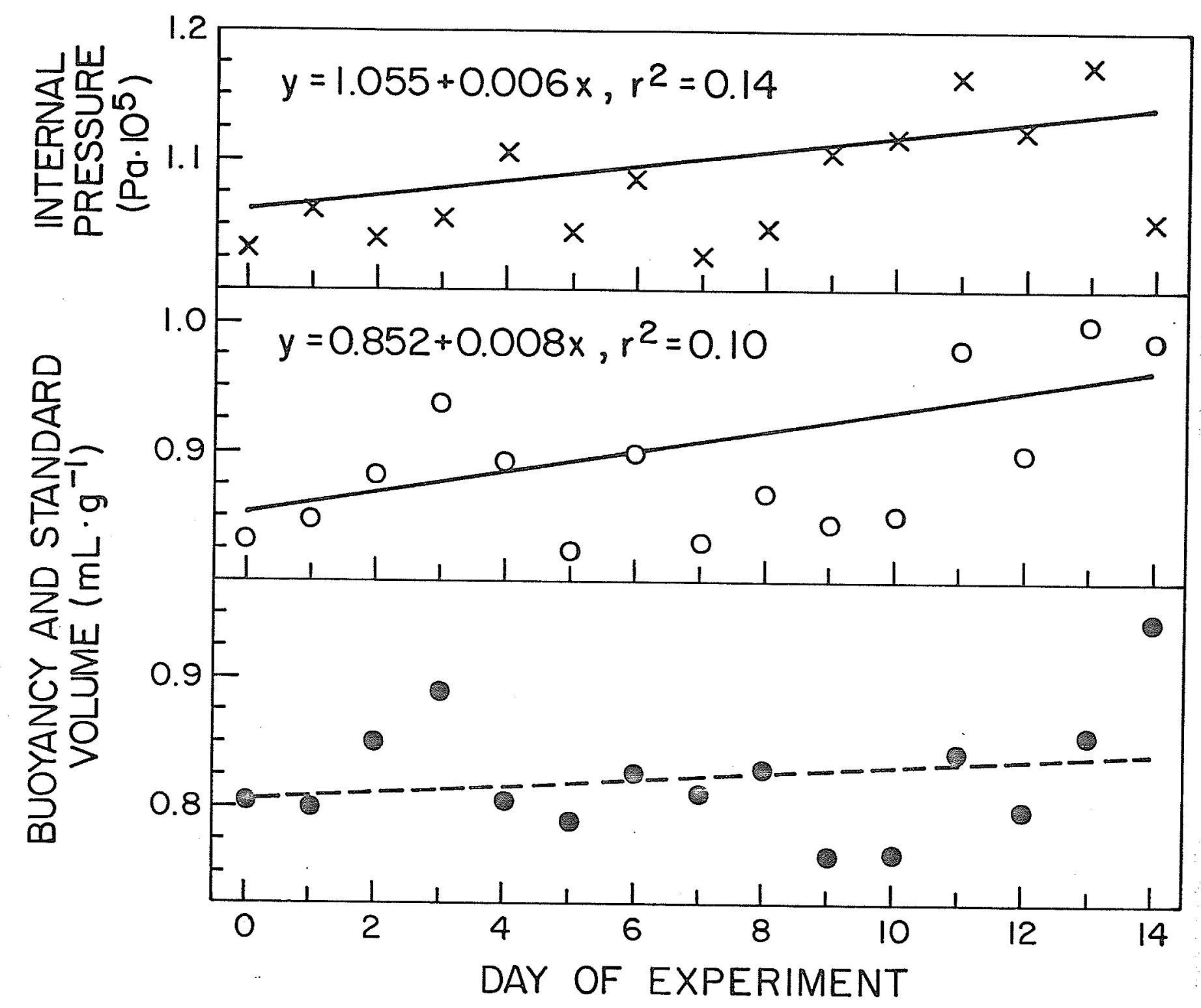

\begin{tabular}{|c|c|c|c|c|c|c|c|c|c|c|c|c|c|c|c|}
\hline $\begin{array}{c}\text { TEMPERATURE } \\
\left({ }^{\circ} \mathrm{C}\right)\end{array}$ & 25 & 26 & 27 & 28 & 29 & 30 & 31 & 31.5 & 32 & 32.5 & 33 & 33.5 & 34 & 34.5 & 35 \\
\hline $\begin{array}{c}\mathrm{H}_{2} \mathrm{O} \text { VELOCITY } \\
\left(\mathrm{cm} \cdot \mathrm{s}^{-1}\right)\end{array}$ & 12.5 & 17.5 & 17.5 & 22.5 & 22.5 & 27.5 & 27.5 & 30 & 30 & 32.5 & 32.5 & 35 & 35 & 35 & 35 \\
\hline
\end{tabular}


Figure 17. Variance of internal pressure measurements vs. mean internal pressure $(n=8)$ for: I. constant water temperature and velocity, II. increasing temperature, III. increasing velocity, and IV. increasing water temperature and velocity. Solid lines are significant. 


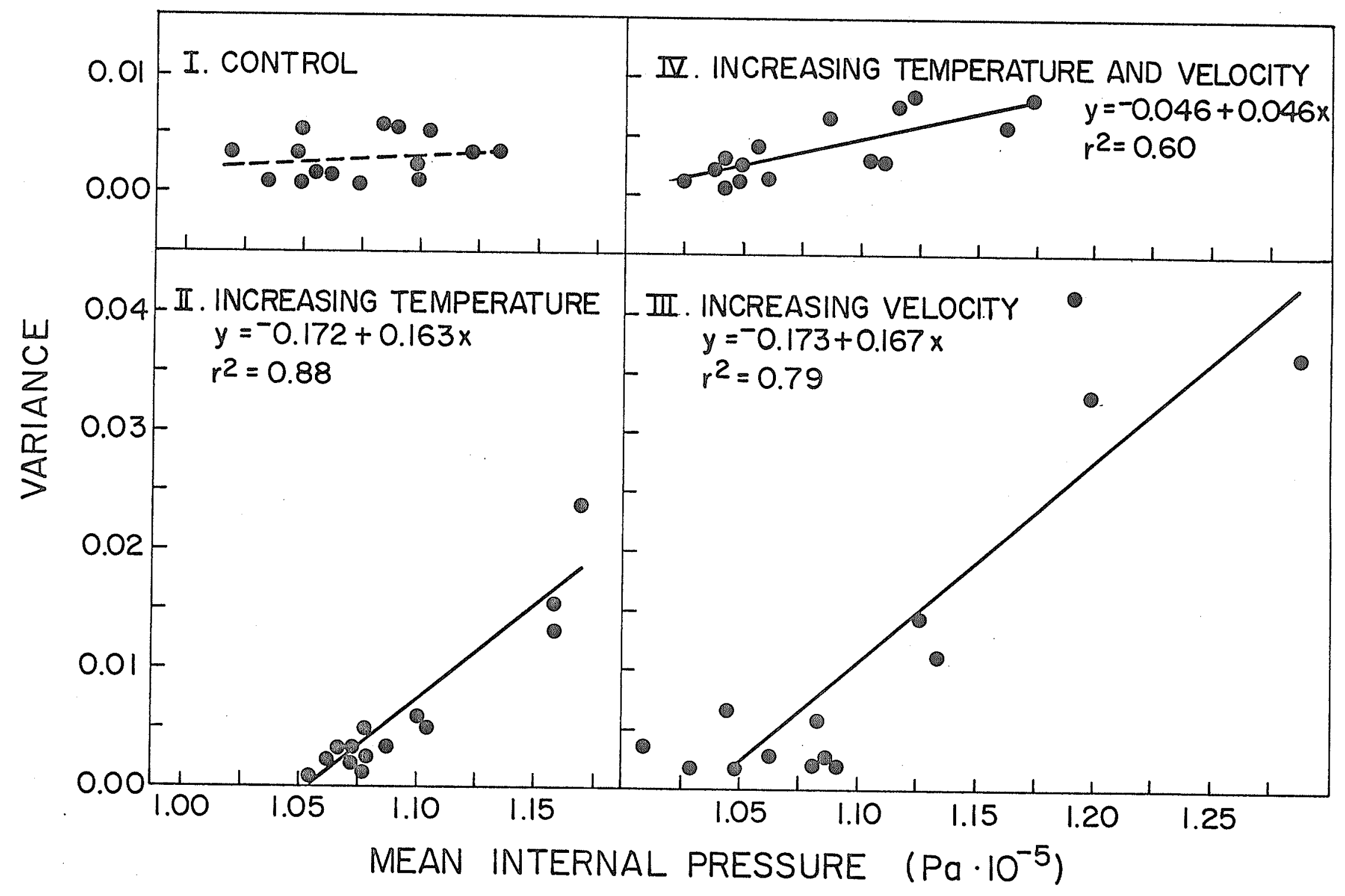




\section{DISCUSSION}

In nature, fish are exposed to fluctuations in water velocity that necessitate alteration of swimbladder volume and buoyancy. If a fish cannot respond to attain the appropriate buoyancy, its swimming effort increases, it may lose position, and its chances of survival and reproduction are diminished. Most buoyancy adjustment is accomplished by gas secretion or absorption and by gulping and spitting gas. Fathead minnows can make extensive adjustments at a rapid rate and maintain the optimal negative buoyancy indefinitely in current.

\section{Mechanisms of Buoyancy Adjustment}

Fathead minnows are able to increase buoyancy by gas secretion from their rete mirabile and by gulping air directly into the swimbladder through the pneumatic duct. They can decrease buoyancy by resorbing gas from the swimbladder and by forcing gas out of the swimbladder through the pneumatic duct. The extent to which each of these mechanisms is used varies between fish. Under extreme conditions, internal pressure may also be altered to help adjust buoyancy. 
When fathead minnows are at less than optimal buoyancy, they increase swimbladder volume quickly by gulping air at the surface and slowly by secreting gas into the swimbladder. Evidence that they secrete gas includes the changing swimbladder gas composition during buoyancy increases and the ability to increase buoyancy without being able to gulp air. Gulping and secretion are used simultaneously to increase buoyancy with observations showing that the former normally accounts for about $70 \%$ of the increase.

If fathead minnows used either mechanism exclusively, and assuming that the increases were linear, they could fill a completely emptied swimbladder in 2.5 h by gulping $(0.42$ $\left.\mathrm{mL} \cdot \mathrm{g}^{-1} \cdot \mathrm{h}^{-1}\right), 24 \mathrm{~h}$ by secretion for small fish $(49-67 \mathrm{~mm}$, $0.042 \mathrm{~mL} \cdot \mathrm{g}^{-1} \cdot \mathrm{h}^{-1}$, and $36 \mathrm{~h}$ by secretion for large fish $\left(72-83 \mathrm{~mm}, 0.028 \mathrm{~mL} \cdot \mathrm{g}^{-1} \cdot \mathrm{h}^{-1}\right)$. Gee's (1977) data give similar results, showing that small fathead minnows (47-63 $\mathrm{mm}, 0.040 \mathrm{~mL} \cdot \mathrm{g}^{-1} \cdot \mathrm{h}^{-1}$ ) can fill their swimbladders completely in $25 \mathrm{~h}$ and juveniles $\left(20-30 \mathrm{~mm}, 0.057 \mathrm{~mL} \cdot \mathrm{g}^{-1} \cdot \mathrm{h}^{-1}\right)$ in $17.5 \mathrm{~h}$. Size related rate differences may reflect the greater relative metabolic and gas uptake rates of smaller fish (Ultsch, 1973; Jones and Randal1, 1978).

These secretion rates are higher than those reported for other physostomes. Mudminnows (Umbra limi) take at least 24 days to completely fill an emptied swimbladder by secretion (Gee, in prep.). Rainbow and brown trout (Salmo

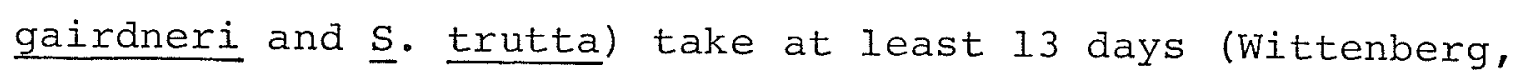


1958), goldfish (Carassius auratus) between 5 and 7 days (Evans and Damant, 1928; Wittenberg, 1958), and longnose dace (Rhinichthys cataractae) between 3 and 4 days to completely fill an emptied swimbladder by secretion (Gee, 1968). When practical, slower secreting fish like muảminnows and rainbow trout fill their swimbladders by gulping air within $20 \mathrm{~min}$ (Gee, pers. comm.). The rete mirabile is generally less well developed than that of physoclists, which are able to fill their swimbladders by gas secretion in 2 to $24 \mathrm{~h}$ (Fange, 1966). Lowering the water temperature may reduce the fathead minnow's rate of buoyancy increase (Gee, 1977), but it does not necessarily mean that secretion rates are altered. As temperature changes, changes in the rate of $0_{2}$ secretion are offset by changes in the rate of $\mathrm{CO}_{2}$ secretion (MCNabb and Mecham, 1971). This may mean that fish are not able to gulp air as effectively at low temperatures.

Little is known about the biochemistry of gas secretion in the physostome swimbladder. Indeed, in many species, researchers have been unable to confirm the existence of gas gland cells (Fange, 1976). Microscopic examination of the fathead minnow swimbladder reveals a well developed system of counter current capillaries which, like those in the eel (Anguilla vulgaris) (Steen, 1963), probably account for the high rate of gas secretion. As in physoclists, most of the newly-secreted gas consists of $\mathrm{O}_{2}$ and $\mathrm{CO}_{2}$, suggesting that 
the secretory mechanisms may also be similar (Wittenberg, 1958; Fange, 1976). Nitrogen concentration in the swimbladder is low following secretion but it slowly rises to the normal still water level by diffusion and secondary $0_{2}$ resorption (Wittenberg, 1958; Alexander, 1966; Enns et al., 1967; Abernethy, 1972). Carbon dioxide diffuses out of the swimbladder following secretion. Still water gas composition ( $1.5 \% \mathrm{CO}_{2}, 11.4 \% \mathrm{O}_{2}, 87.1 \% \mathrm{~N}_{2}$ ) closely resembles that reported for two other physostomes, the shallowwater cisco (Leucichthys artedi: $1.6 \% \mathrm{CO}_{2}, 10.7 \% 0_{2}, 87.7 \% \mathrm{~N}_{2}$ ' and the American smelt (Osmerus mordax: $1.0 \% \mathrm{C}_{2}, 11.2 \% 0_{2}, 87.9 \% \mathrm{~N}_{2}$ ) (Saunders, 1953). When fathead minnows are too buoyant, they can decrease swimbladder volume quickly by spitting gas bubbles or slowly by resorbing gas from the swimbladder. The former is used in response to fright; the latter is the main mechanism used to reduce swimbladder volume in response to an increase in water velocity. This is evidenced by the lack of spitting when current is increased and the change in composition of swimbladder gases. This change is opposite that which occurs during secretion. High $\mathrm{N}_{2}$ and low $\mathrm{O}_{2}$ and $\mathrm{CO}_{2}$ concentrations following buoyancy reduction suggest that gas is removed from the swimbladder by diffusion. This is supported by the fact that $\mathrm{CO}_{2}$ diffuses out of the swimbladder faster than $\mathrm{O}_{2}$ which diffuses faster than $\mathrm{N}_{2}$ (Piiper et al., 1962; Kutchai and 
Steen, 1971; Denton et al., 1972). Thus, $\mathrm{N}_{2}$ concentration rises as $\mathrm{O}_{2}$ and $\mathrm{CO}_{2}$ are preferentially resorbed. During exposure to current, fish were observed occasionally to gulp air at the surface. If it was taken into the swimbladder, buoyancy should have increased. It did not and this may mean that air was taken into the swimbladder where the $\mathrm{O}_{2}$ and $\mathrm{CO}_{2}$ were removed by resorption. Since $0_{2}$ consumption in current is one of the limiting factors to swimming performance, having the ability to supplement $0_{2}$ uptake during strenuous swimming, especially at non-optimal temperatures, would be a great survival advantage (Brett, 1964, 1972). The rate of gas resorption appears to be independent of temperature (Gee, 1977). Small fathead minnows $(47-67 \mathrm{~mm})$ can halve the volume of gas in their swimbladders using mainly resorption in 15 to $22 \mathrm{~h}\left(0.034-0.023 \mathrm{~mL} \cdot \mathrm{g}^{-1} \cdot \mathrm{h}^{-1}\right)$. If they are forced to spit gas they can halve their swimbladder volume without injury in less than $10 \mathrm{~min}$.

Under extreme conditions, fathead minnows appear to contract or expand swimbladder volume by muscular activity, decreasing or increasing buoyancy. This is evidenced by changes in the internal pressure and has been observed to occur in several other species of physostomes and in some physoclists (McCutcheon, 1962; Gee, 1970; Gee et al.,1974). This method can only be used to alter buoyancy over a small range. It is used when fish are first exposed to current

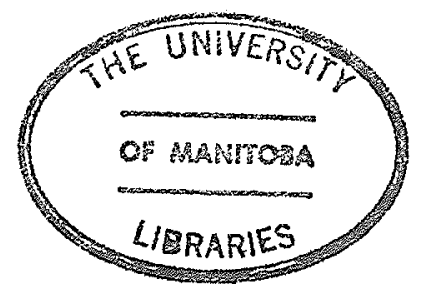


and when water temperature and/or velocity are high and increasing. During the initial stages of buoyancy decrease, altering the internal pressure may prevent unnecessary gas resorption where buoyancy need only be altered for a short period. Under stressful conditions, internal pressure alterations, though slight, may be critical to the adjustment of swimbladder volume and buoyancy. The use of internal pressure may be limited to short term buoyancy adjustments by the energy cost of maintaining muscular tonus. Such short term adjustments may improve the precision of buoyancy control (McCutcheon, 1962).

Fathead minnows can alter swimbladder volume to adjust buoyancy by resorption/secretion, spitting/gulping and also by altering internal pressure of swimbladder gas. The former two mechanisms are used for major changes, the latter is used sparingly - usually for minor adjustments. There are advantages and disadvantages to each of these methods. Spitting and gulping have the advantage of changing buoyancy rapidly. They have the disadvantage of imprecision and gulping also requires time and energy to go to the surface, it exposes the fish to predators, and it is difficult when ice is present. Gulping air at atmospheric pressure also makes it difficult to obtain sufficient gas to maintain neutral buoyancy at depths where pressures are much greater than atmospheric. Secretion and resorption while slower have none of these disadvantages. Internal pressure alterations have 
the advantage that they do not require gas exchange and the disadvantages of being energetically expensive and causing only limited swimbladder volume and buoyancy changes.

The mechanisms used to inflate or deflate the swimbladder may be influenced by several environmental factors. For example, predator disturbance may cause buoyancy reduction by spitting; it is fast, allowing fish to quickly seek cover on the bottom or at the surface and precision is not important (Jones, 1951, 1957; Verheijen, 1962; McCutcheon, 1966; Sullivan and Atchison, 1978). Fish entering current from still water resorb gas, tailoring buoyancy precisely to the level where swimming is most efficient. Ice cover may necessitate secretion under some conditions and fish far below the surface may secrete rather than swim to the surface to gulp. Following predator exposure and buoyancy reduction, it might be advantageous for fish to quickly return to neutral buoyancy by gulping air at the surface. In this event, adaptations such as group surfacing might be used to reduce exposure to predators (Gee, in press). Reducing buoyancy for short periods by increasing internal pressure might be advantageous for fish swimming from one pool to another up a riffle. 
They would swim efficiently in the current of the riffle without having to gulp or secrete gas when they reached the upper pool. Having a choice of mechanisms available may in itself be advantageous as the fish can use that strategy which is safest and most efficient under the prevailing environmental conditions.

\section{Ability to Maintain Buoyancy}

Fathead minnows can maintain a buoyancy level appropriate to the hydraulic demands of their environment for at least 42 days. Two of the factors determining the level attained are water temperature and velocity. In near lethal combinations, or when temperature is low, they may cause buoyancy maintenance to fail (Berezay and Gee, 1978).

Fish make buoyancy alterations to counteract the changing forces of lift on their bodies, thereby reducing swimming effort required to maintain position. Because lift forces do not change unless the hydraulic forces on the fish's body change, to maximize swimming efficiency in constant conditions fish should maintain a constant buoyancy. Lift forces ( $F_{L}$ ) are determined by the density of the fish $(\rho)$, the maximum projected surface area $\left(S_{h}\right)$, swimming speed (U), and the coefficient of lift $\left(C_{I}\right)$; where $C_{I}$ equals a constant for a given hyarofoil shape (k) multiplied by the sine of the 
swimming angle of attack $(\alpha)$. This results in the equation:

$$
\mathrm{F}_{\mathrm{L}}=\frac{1}{2} \rho \mathrm{S}_{\mathrm{h}} \mathrm{U}^{2} \mathrm{C}_{\mathrm{L}} \quad(\text { Webb, 1975). }
$$

Based on this information, lift and therefore buoyancy should change quadratically as the inverse of the water velocity when all other factors are constant. In practice, there is only a simple inverse linear relationship between buoyancy and water velocity. It holds over the long term at $30^{\circ} \mathrm{C}$ between velocities of 10 and $30 \mathrm{~cm} \cdot \mathrm{s}^{-1}$ and for increasing water velocities when temperature is a constant $25^{\circ} \mathrm{C}$. Gee (1977) working with fathead minnows at $21^{\circ} \mathrm{C}$ and Neave et al. (1966) working with salmon parr also found that buoyancy was inversely related to water velocity with a linear relationship existing. Why buoyancy changes are linear and not quadrat as predicted by Webb's (1975) model remains unclear.

The lack of relationship between buoyancy and velocity observed at $21^{\circ} \mathrm{C}$ is puzzling. It is contrary to other observations and suggests that some other factor influences buoyancy at that temperature. Since $21^{\circ} \mathrm{C}$ is the optimal temperature for swimming performance and reproduction in the fathead minnow (Brungs, 1971; Gee, 1977), it may be that fish expend less energy swimming and consequently the energy saved by fine buoyancy adjustments is unimportant.

The relationship between temperature and buoyancy level is not a simple one. Average buoyancies were higher at 5 and $26^{\circ} \mathrm{C}$ than at 11,21 and $30^{\circ} \mathrm{C}$. Gee (1977) obtained 
similar results except that buoyancy remained low at 24 and $27^{\circ} \mathrm{C}$ after 3 days in current. Since increasing water temperature from 25 to $34.5^{\circ} \mathrm{C}$ while holding velocity constant also had no effect on buoyancy level, other temperature dependent factors may have been operating at $26^{\circ} \mathrm{C}$. Neither season of the year, degree of gonad development, condition, nor photoperiod which were found to affect buoyancy (Luoma, 1979) can explain why buoyancy should be higher than expected at $26^{\circ} \mathrm{C}$. The inability to reduce buoyancy to the same extent at $5^{\circ} \mathrm{C}$ as at higher temperatures and to maintain it within narrow limits over a long period, may mean that only at low temperatures are fathead minnows unable to respond to lift created by increasing water currents. Why this should be so has yet to be explained. Since low temperatures encountered in nature are often coincident with spring run-off, fish unable to reduce their buoyancy at low temperatures risk being swept downstream.

In current, the initial buoyancy reduction takes less than $24 \mathrm{~h}$ but it appears to be approximate. Adjustments continue for between 4 and 18 days until a buoyancy level appropriate to the water temperature and velocity is reached. Following adjustment, buoyancy is usually maintained at a constant low level. During maintenance, buoyancy fluctuations occur both within and between sampling days. These follow 
no set pattern and probably reflect minor changes in the test conditions and/or in the groups of fish tested. Most buoyancy differences between temperatures and velocities result from differences in the amount (standard volume) of gas in the swimbladder and not in the internal pressure. However, during the initial buoyancy decrease and at high temperatures, internal pressure may also be altered.

Stress, as defined by Brett (1958), is a state produced by any environmental or other factor which extends the adaptive responses of an animal beyond the normal range or which disturbs the normal functioning to the extent that, in either case, the chances of survival are significantly reduced. Two environmental stressors are high water temperature and velocity.

When fish are stressed by increasing water temperature and/or velocity, to near lethal levels, internal pressure plays a much greater role in determining buoyancy levels. It increases when temperature or both temperature and velocity are increased, offsetting increases in standard volume and keeping buoyancy level constant. When velocity alone increases, internal pressure rises as standard volume falls, increasing the extent of buoyancy adjustments. Internal pressure may be a good indicator of sublethal temperature and velocity stress. Initially, variability 
is uniformly low as all of the fish can regulate their internal pressure. Then, as temperature reaches $32.5^{\circ} \mathrm{C}$ or velocity $30 \mathrm{~cm} \cdot \mathrm{s}^{-1}$, variability increases as some fish lose their ability to control internal pressure. Finally, at extreme temperatures and velocities $\left(34.5^{\circ} \mathrm{C}, 35 \mathrm{~cm} \cdot \mathrm{s}^{-1}\right.$ ), all of the fish lose control of their internal pressure and variability is again low. When control is lost, buoyancy often rises abruptly. It would be interesting to determine whether sublethal chemical stressors have similar effects.

It is interesting that effects of stress from increasing water temperature and velocity simultaneously are not cumulative. Fish either no longer can or no longer need to reduce buoyancy in response to increasing current when temperature is also increasing. Several observations suggest that the latter is the correct explanation. Internal pressure variability was generally low, fish did not appear to be labouring while swimming in current, and there were no mortalities. Perhaps the combination of high temperature and velocity cause a slight change in the fish's body shape, thereby reducing lift and the need to compensate by reducing buoyancy. Fish swimming in current also appear to withstand higher temperatures than those in still water. On one occasion temperature was raised to $37^{\circ} \mathrm{C}$ overnight and fish in current all survived with no obvious ill affects. The still water lethal level is 
reported to be $34^{\circ} \mathrm{C}$ (Brett, 1944; Hart, 1947; Brungs, 1971). These differences may be partially due to the greater oxygen availability in current than in still water at high temperatures. The effects of increasing water temperature and velocity simultaneously, then, appear to be antagonistic (Sprague, 1970).

Fathead minnows can maintain buoyancy in current over long periods. This ability enables them to swim efficiently in current, facilitating migrations upstream to more desirable habitats and preventing them from being swept downstream to less desirable habitats where they would be more susceptible to predation and extinction. North temperate streams are characterized by rapid changes in time and space of water velocity and many have a prolonged interval of spring run-off. The fathead minnow is adapted to such an environment partially because it can adjust buoyancy rapidly and maintain a negative buoyancy for an extended period. 
REFERENCES

Abernethy, J. D. 1972. The mechanism of secretion of inert gas into the fish swimbladder. Aust. J. Exp. Biol. Med. Sci. 50:365-374.

Alexander, R. MCN. 1966. Physical aspects of swimbladder function. Biol. Rev. (1966):141-176.

Berezay, G. and J. H. Gee. 1978. Buoyancy response to changes in water velocity and its function in creek chub (Semotilus atromaculatus). J. Fish. Res. Bd. Canada $35: 295-299$.

Brett, J. R. 1944. Some lethal temperature relations of Algonquin Park fishes. Ontario Fish. Res. Lab. Publ. 63 (Univ. of Toronto stud. Biol. Ser. 52), 49 p. Brett, J. R. 1958. Implications and assessments of environmental stress, p. 69-83. In P. A. Larkin (ed.), The investigation of fish power problems. University of British Columbia, Vancouver.

Brett, J. R. 1964. The respiratory metabolism and swimming performance of young sockeye salmon. J. Fish. Res. Bd. Canada 21 (5): 1183-1226.

Brett, J. R. 1972. The metabolic demand for oxygen in fish, particularly salmonids, and a comparison with other vertebrates. Respir. Physiol. 14:151-170.

Brungs, W. A. 1971. Chronic effects of constant elevated temperature on the fathead minnow (Pimephales promelas). Trans. Am. Fish. Soc. 1971 (4):659-664. 
Denton, E. J., J. D. Liddicoat, and D. W. Taylor. 1972. The permeability to gases of the swimbladder of the conger eel (Conger conger). J. Mar. Biol. Assn. U.K. $52: 727-746$.

Enns, T., E. Douglas, and P. F. Scholander. 1967. Role of the swimbladder rete of fish in secretion of inert gas and oxygen. Adv. Biol. Med. Physics 11:231-244.

Evans, H. R. and G. C. C. Damant. 1928. Observations on the physiology of the swimbladder in cyprinid fishes. Brit. J. Exp. Biol. 6:42-55.

Fange, R. 1966. Physiology of the swimbladder. Physiol. Rev. $46: 299-332$.

Fange, R. 1976. Gas exchange in the swimbladder, p. 189211. In G. M. Hughes (ed.) Respiration of amphibious vertebrates. Academic Press, London.

Gee, J. H. 1968. Adjustment of buoyancy by Iongnose dace (Rhinichthys cataractae) in relation to velocity of water. J. Fish. Res. Bd. Canada 25(7):1485-1496.

Gee, J. H. 1970. Adjustment of buoyancy in blacknose dace, (hinichthys atratulus) . J. Fish. Res. Bd. Canada $27: 1855-1859$.

Gee, J. H. 1972. Adaptive variation in swimbladder length and volume in dace, genus Rhinichthys. J. Fish. Res. Bd. Canada 29:119-127.

Gee, J. H. 1974. Behavioural and developmental plasticity of buoyancy in the longnose, Rhinichthys cataractae, and blacknose, $\underline{R}$ atratulus (Cyprinidae) dace. J. Fish. Res. Bd. Canada 31:35-41. 
Gee, J. H. 1977. Effects of size of fish, water temperature and water velocity on buoyancy alteration by fathead minnows, Pimephales promelas. Comp. Biochem. Physiol. 56(4A):503-508.

Gee, J. H. 1980. Respiratory patterns and antipredator responses in the central mudminnow, Umbra limi, a continuous, facultative, air breathing fish. Can. J. Zool. 58 (In Press).

Gee, J. H. and V. G. Bartnik. 1969. Simple stream tank simulating a rapids environment. J. Fish. Res. Bd. Canada $26: 2227-2230$.

Gee, J. H. and P. A. Gee. 1976. Alteration of buoyancy by some Central American stream fishes, and a comparison with North American species. Can. J. Zool. 54:386-391.

Gee, J. H. and J. B. Graham. 1978. Respiratory and hydrostatic functions of the intestine of the catfishes Hoplosternum thoracatum and Brochis splendens (Callichthyidae). J. Exp. Biol. 74:1-16.

Gee, J. H., K. Machniak, and S. M. Chalanchuk. 1974. Adjustment of buoyancy and excess internal pressure of swimbladder gases in some North American freshwater fishes. J. Fish. Res. Bd. Canada 31:1139-1141.

Hart, J. S. 1947. Lethal temperature relations of certain fish of the Toronto region. Trans. Roy. Soc. Can. 41 (Ser. 111, Sect. 5):57-71.

Jones, D. R. and D. J. Randall. 1978. The respiratory and circulatory systems during exercise, p. 425-501. In 
W. S. Hoar and D. J. Randall (eds.), Fish physiology, Vol. VII Locomotion, Academic Press, New York. Jones, F. R. H. 1951. The swimbladder and the vertical movements of teleostean fishes. I. Physical factors. J. Exp. Biol. 28:553-566.

Jones, F. R. H. 1957. The swimbladder, pp. 305-322. In M. E. Brown (ed.), The physiology of fishes. Academic Press. New York.

Kutchai, H. and J. P. Steen. 1971. The permeability of the swimbladder. Comp. Biochem. Physiol. 39A:119-123. Luoma, M. E. 1979. Seasonal factors affecting the buoyancy attained in still water and in current by fathead minnows, Pimephales promelas. M.Sc. Thesis, Univ. of Manitoba, Winnipeg. $79 \mathrm{p}$.

Luoma, M. E. and J. H. Gee. 1980. Seasonal factors affecting buoyancy attained in still water and current by fathead minnows, Pimephales promelas. Can. J. Fish. Aquat. Sci. 37:670-678.

McCutcheon, F. H. 1962. Swimbladder volume control in the pinfish, Lagodon rhornboides (Linn.). J. Cell. Comp. Physiol. 59:203-214.

McCutcheon, F. H. 1966. Pressure sensitivity, reflexes, and buoyancy responses in teleosts. An. Behav. 14:204-217. McNabb, R. A. and J. A. Mecham. 1971. The effects of different acclimation temperatures on gas secretion in the swimbladder of the bluegill sunfish, Lepomis macrochirus. Comp. Biochem. Physiol. 40A:609-616. 
McNair, H. M. and E. J. Bonelli. 1969. Basic gas chromatography. Consolidated Printers, Berkeley. $306 \mathrm{p}$.

Neave, N. M., C. L. Dilworth, J. G. Eales, and R. L. Saunders. 1966. Adjustment of buoyancy in Atlantic salmon parr in relation to changing water velocity. J. Fish. Res. Bd. Canada. 23:1617-1620.

Piiper, J., H. T. Humphrey, and H. Rhan. 1962. Gas composition of pressurized, perfused gas pockets and the fish swimbladder. J. Appl. Physiol. $17(2): 275-282$.

Pinder, L. J., and J. G. Eales. 1969. Seasonal buoyancy changes in Atlantic salmon (Salmo salar) parr and smolt. J. Fish. Res. Bd. Canada 26:2093-2100.

Saunders, R. L. 1953. The swimbladder gas content of some freshwater fish with particular reference to the physostomes. Can. J. Zool. 31:547-560.

Saunders, R. L. 1965. Adjustment of buoyancy in young Atlantic salmon and brook trout by changes in swimbladder volume. J. Fish. Res. Bd. Canada 22:335-352.

Scott, W. B., and E. J. Crossman. 1973. Freshwater fishes of Canada. Fisheries Research Board of Canada, Ottawa, Bulletin 184. $966 \mathrm{p}$.

Sprague, J. B. 1970. Measurement of pollutant toxicity to fish. II. Utilizing and applying bioassay results. Water Research 4:3-32. 
Sullivan, J. F. and G. J.Atchison. 1978. Predator-prey behavior of fathead minnows, Pimephales promelas and large-mouth bass, Micropterus salmoides in a model ecosystem. J. Fish Biol. 13(2):249-253.

Steen, J. B. 1963. The physiology of the swimbladder of the eel Anguilla vulgaris. Acta. Physiol. Scand. 59:221-24l. Ultsch, G. R. 1973. A theoretical and experimental investigation of the relationship between metabolic rate, body size, and oxygen exchange capacity. Respir. Physiol. 18:143-160.

Verheijen, F. J. 1962. Gas spitting by alarmed fish disturbs their hydrostatic equilibrium. Sc. 137:864-865.

Webb, P. W. 1975. Hydrodynamics and energetics of fish propulsion. Fisheries Research Board of Canada, Ottawa, Bulletin 190. $158 \mathrm{p}$.

Wittenberg, J. B. 1958. The secretion of inert gas into the swimbladder of fishes. J. Gen. Physiol. 41:783-804. 
$\begin{array}{llllllllll}A & P & P & E & N & D & I & C & E & S\end{array}$ 


\section{APPENDIX 1}

Gas volume corrections and sample calculations.

Gases released from the swimbladder during collection were subject to changes in pressure, temperature, and volume. To determine the effects of thermal expansion-contraction, gas diffusion into the water bath, and water column height in the collecting pipette on gas released from the swimbladder, a test experiment was performed.

In the test experiment, conditions were exactly similar to those of actual swimbladder gas volume measurements except that known gas volumes were released. Fifty and $100 \mu \mathrm{L}( \pm 1$ percent) air samples were released under water at $5,10,15,20,25,30$, and $35^{\circ} \mathrm{C}$ and collected in an inverted funnel. They were then measured at $22.2^{\circ} \mathrm{C}$ in a $200 \mu L$ ( \pm 8 percent) pipette attached to the funnel. Eight measurements of 100 uL samples were made at each temperature using 2 different pipettes, $A$ and B, and similar measurements of $50 \mu \mathrm{L}$ samples were made with pipette A. Pipette $A$ was used for all previous experimentation.

Gas volumes released differed from those collected both with temperature and between pipettes (Table Al). There were no measureable gas volume changes arising from solubility, diffusion or from expansion due to water column pressure in the pipette. Volumes of 50 and $100 \mu \mathrm{L}$ changed the same relative amount with temperature and while pipette A and $B$ showed similar slopes with temperature, their $y$-intercepts differed markedly. 
Table Al. Regression equations testing for gas sampling errors. Asterisk (*) indicates statistical significance $(P<0.05)$.

\begin{tabular}{|c|c|c|c|c|c|}
\hline $\begin{array}{l}\text { Pipette and } \\
\text { Gas Volume } \\
\text { Released }\end{array}$ & $y$-intercept & $\begin{array}{c}\text { slope } \\
\left(\mu \mathrm{L} \cdot{ }^{\circ} \mathrm{C}^{-1}\right)\end{array}$ & F. Calc. & F. Crit. & $\mathrm{R}^{2}$ \\
\hline $\begin{array}{l}\text { pipette A- } \\
100 \mathrm{ML}\end{array}$ & $116.3 \mathrm{\mu L}$ & -0.3964 & $1302.7 *$ & 4.06 & 0.960 \\
\hline $\begin{array}{l}\text { pipette B- } \\
100 \mathrm{ML}\end{array}$ & $108.4 \mathrm{\mu L}$ & -0.3054 & $612.3 *$ & 4.06 & 0.919 \\
\hline $\begin{array}{l}\text { pipette A- } \\
50 \mathrm{uL} \cdot 2\end{array}$ & 115.3 uL & -0.3732 & $538.2 *$ & 4.06 & 0.909 \\
\hline $\begin{array}{l}\text { regression for } \\
\text { pipette } A \\
\text { based on error } \\
100 \mathrm{NL}\end{array}$ & $115.6 \mathrm{\mu L}$ & -0.3514 & & & \\
\hline
\end{tabular}

Table A2. Correction factors for gas volumes released from the swimbladder.

\begin{tabular}{rccc}
\hline $\begin{array}{l}\text { Temperature } \\
\text { of Fish } \\
\left({ }^{\circ} \mathrm{C}\right)\end{array}$ & $\begin{array}{c}\text { Correction } \\
\text { Factor }\end{array}$ & $\begin{array}{l}\text { Temperature } \\
\text { of Fish } \\
\left({ }^{\circ} \mathrm{C}\right)\end{array}$ & $\begin{array}{c}\text { Correction } \\
\text { Factor }\end{array}$ \\
\hline 5 & 1.143 & 31 & 1.040 \\
11 & 1.119 & 31.5 & 1.038 \\
19 & 1.088 & 32 & 1.036 \\
21 & 1.080 & 32.5 & 1.034 \\
25 & 1.064 & 33 & 1.032 \\
26 & 1.060 & 33.5 & 1.030 \\
27 & 1.056 & 34 & 1.028 \\
28 & 1.052 & 34.5 & 1.026 \\
29 & 1.048 & 35 & 1.024 \\
30 & 1.044 & & \\
\hline
\end{tabular}


The results suggested that volumetric errors in the gas measurement were due to volumetric errors in the pipettes and thermal expansion or contraction of the gas. For pipette A, the collected volume of a 100 dL sample, held and measured at $22.2^{\circ} \mathrm{C}$, was $107.5 \mu \mathrm{L}$ (i.e., $\mathrm{y}=116.3 \mu \mathrm{L}-$ $\left.0.3964 \mu \mathrm{L}^{\circ} \mathrm{C}^{-1} \cdot 22.2^{\circ} \mathrm{C}\right)$. This positive 7.5 percent error in the pipette, coupled with thermal contraction $(1.0 \mu \mathrm{L}=$ $(273 \mathrm{~K}+22.2 \mathrm{~K}) \div(273 \mathrm{~K}+35 \mathrm{~K})=0.9584 \mu \mathrm{L})$ or expansion $(1.0 \mu L=(273 K+22.2 K) \div 273 K+5.0 K)=1.0619 \mu L)$, yielded a regression equation within 1 percent of the observed regression for pipette $A$, confirming the sources of gas measurement error (Figure Al, Table Al). Both sources of measurement error and the daily barometric pressures were corrected for in the internal pressure and standard volume measurements. For example:

$$
\begin{aligned}
\text { Fish C: } & \text { held at } 25^{\circ} \mathrm{C} \\
& - \text { body weight } 1.848 \mathrm{~g} \\
& - \text { weight in water }+ \text { swimbladder } 0.023 \mathrm{~g} \\
& - \text { weight in water }- \text { swimbladder } 0.103 \mathrm{~g} \\
- & \text { gas volume released from swimbladder } 0.092 \mathrm{~mL} \\
- & \text { swimbladder displacement volume } 0.080 \mathrm{~mL} \\
\text { Buoyancy }= & \quad \text { Swimbladder volume }=\frac{0.080 \mathrm{~mL}}{0.103 \mathrm{~g}}=0.777 \mathrm{~mL} \cdot \mathrm{g}-1 \\
& \text { Without Swimbladder } \\
- & \text { measures the flotation per gram weight of } \\
& \text { fish tissue in water, independent of } \\
& \text { temperature and pressure. }
\end{aligned}
$$


Figure Al. Measured and predicted error in gas sample volume measurements arising from gas contraction and expansion with temperature changes and from errors in the pipette volume. 


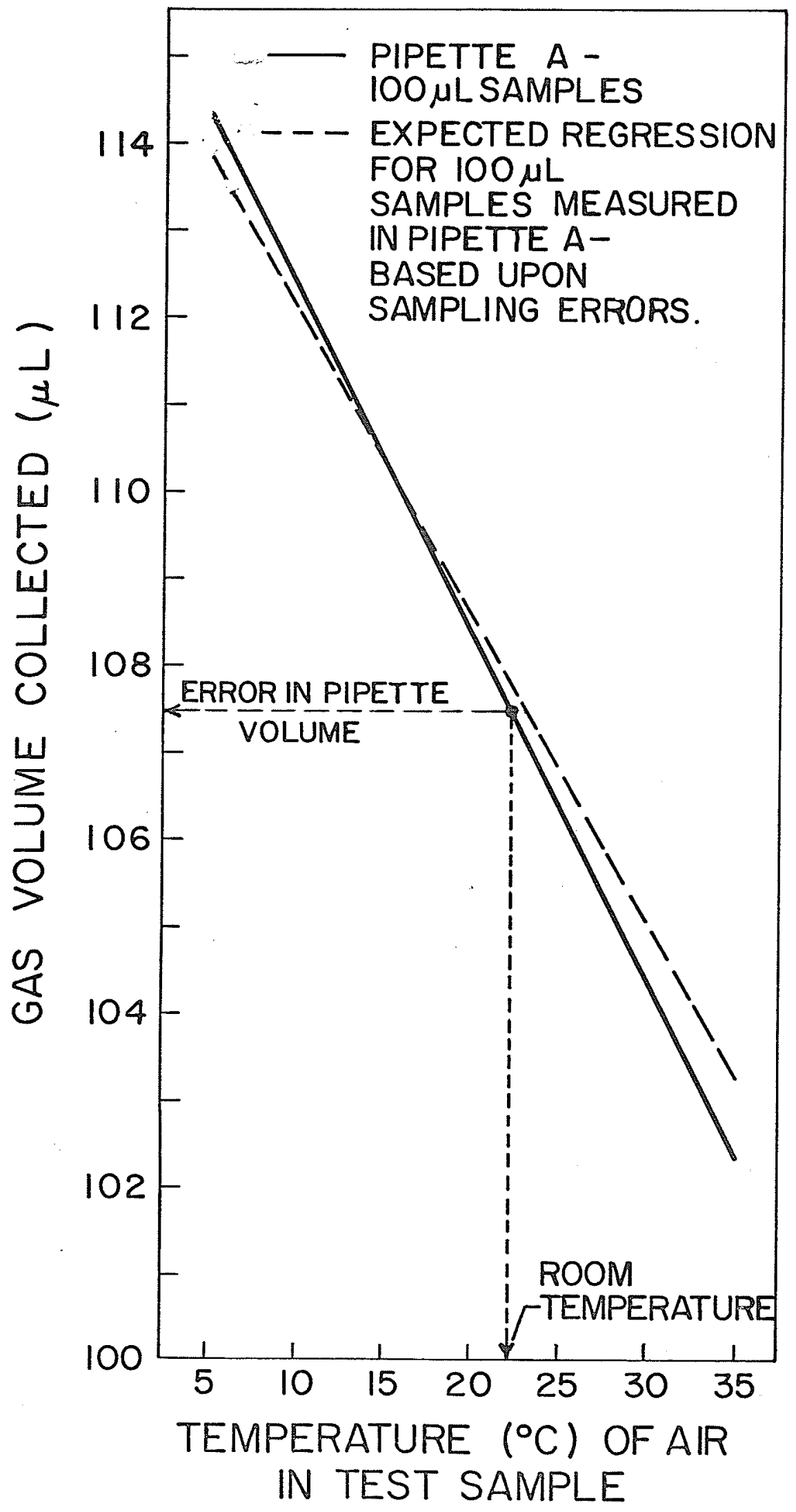




$$
\begin{aligned}
& \text { Internal Pressure }=\frac{\text { Gas Volume Released }}{\text { Swimbladder Volume }} \\
& =\frac{0.092 \mathrm{~mL}}{0.080 \mathrm{~mL}}=1.150 \text { Atmospheres }
\end{aligned}
$$


- measures the gas volume released (at $25^{\circ} \mathrm{C}$ and standard pressure) per gram weight in water. It allows comparison of the relative amount of gas in the swimbladder between temperatures, not of the moles of gas in the swimbladder. 
Percentage of Fish Swimming Horizontally, Mean Buoyancy $\left(\mathrm{mL} \cdot \mathrm{g}^{-1}, \mathrm{n}=8\right.$ ) and $95 \circ$ Confidence Intervals (CI) During Adjustment to still Water
and Current at $19^{\circ} \mathrm{C}$.

\begin{tabular}{|c|c|c|c|c|c|c|}
\hline & $\begin{array}{l}\text { Time } \\
(\mathrm{h})\end{array}$ & $\begin{array}{l}\text { Percent } \\
\text { Swimming } \\
\text { Horizontally }\end{array}$ & $\begin{array}{l}\text { Mean } \\
\text { Buoyancy } \\
\left(\mathrm{mL} \cdot \mathrm{g}^{-1}\right)\end{array}$ & $\begin{array}{l}\text { Standard } \\
\text { Deviation }\end{array}$ & $\begin{array}{l}95 \% \\
\text { For }\end{array}$ & $\begin{array}{l}C I \\
\text { Mean }\end{array}$ \\
\hline \multirow[t]{6}{*}{ Current } & 0.5 & 50.0 & 0.720 & 0.138 & 0.604 & -0.835 \\
\hline & 1.5 & 55.2 & 0.705 & 0.123 & 0.602 & -0.808 \\
\hline & 2.5 & 61.2 & 0.657 & 0.120 & 0.557 & -0.757 \\
\hline & 5.5 & 75.0 & 0.600 & 0.096 & 0.520 & -0.681 \\
\hline & 8.5 & 77.5 & 0.619 & 0.126 & 0.514 & -0.72 .5 \\
\hline & 11.5 & 85.0 & 0.596 & 0.134 & 0.484 & -0.708 \\
\hline \multirow{6}{*}{$\begin{array}{l}\text { Still } \\
\text { Water }\end{array}$} & 0.5 & 44.2 & 0.653 & 0.120 & 0.553 & -0.753 \\
\hline & 1.5 & 48.5 & 0.653 & 0.145 & 0.532 & -0.775 \\
\hline & 2.5 & 54.0 & 0.612 & 0.154 & 0.484 & -0.741 \\
\hline & 5.5 & 76.8 & 0.794 & 0.127 & 0.687 & -0.900 \\
\hline & 8.5 & 87.0 & 0.849 & 0.153 & 0.722 & -0.977 \\
\hline & 11.5 & 87.5 & 0.852 & 0.114 & 0.757 & -0.947 \\
\hline
\end{tabular}

Regression Analyses Tables: (See Note, page 14)

Percent of Fish Swimming Horizontally vs. Mean Buoyancy $\left(\mathrm{mL} \cdot \mathrm{g}^{-1}\right.$ ) During Adjustment to $20 \mathrm{~cm} \cdot \mathrm{s}^{-1}$ Current.

\begin{tabular}{lccccc}
\hline Source & df & ss & mss & F.Calc. & F.Crit. \\
\hline Total & 5 & 0.0144 & 0.0029 & & \\
Regression & 1 & 0.0133 & 0.0133 & $52.02 *$ & 7.71 \\
Residual & 4 & 0.0010 & 0.0003 & $* \star$ &
\end{tabular}

Regression Equation: $y=0.9004-0.0037 x, r^{2}=0.964$

Percent of Fish Swimming Horizontally vs. Mean Buoyancy $\left(\mathrm{mL}^{-1} \mathrm{~g}^{-1}\right.$ ) During Adjustment to still water Following Exposure to $20 \mathrm{~cm} \cdot \mathrm{s}^{-1}$ Current.

\begin{tabular}{lccccc}
\hline Source & df & ss & mss & F. Calc. & F. Crit. \\
\hline Total & 5 & 0.0587 & 0.0118 & & \\
Regression & 1 & 0.0539 & 0.0539 & $44.73^{*}$ & 7.71 \\
Residual & 4 & 0.0048 & 0.0012 & $* *$ &
\end{tabular}

Regression Equation: $y=0.3834+0.0053 x, x^{2}=0.918$

** No repeats lack of fit tests not possible. 


\section{APPENDIX 3}

Regression Analyses of Fish Length (nm) vs. Rate of Buoyancy Increase by Gas Secretion $\left(\mathrm{mL} \cdot \mathrm{g}^{-1} \cdot \mathrm{h}^{-1}\right)$. (See Note, page 14)

\begin{tabular}{lccccc}
\hline Source & df & ss & mss & F.Calc. & F.Crit. \\
\hline Total & 7 & 0.00045 & 0.00006 & & \\
Regression & 1 & 0.00034 & 0.00034 & $18.82 *$ & 5.99 \\
Residual & 6 & 0.00011 & 0.00002 & & \\
Lack of Fit & 5 & 0.00011 & 0.00002 & 43.40 & 230.0 \\
Pure Error & 1 & 0.00000 & 0.00000 & & \\
\hline
\end{tabular}

Regression Equation: $\quad y=0.0700-0.0005 x, r^{2}=0.76$

A one-way ANOVA comparing the volumes of gas bubbles forced into the swimbladder (gulps)

found that large fish $(72-83 \mathrm{~mm})$ gulped

significantly greater amounts of gas on the

average than did small fish $(49-67 \mathrm{~mm})$

$\left(\mathrm{F}_{\text {Calc. }}=39.5 *, \mathrm{~F}_{0.05,1,6}=5.99\right)$. 


\section{APPENDIX 4}

Two-Way Analyses of Variance: Buoyancies $\left(\mathrm{mL} \cdot \mathrm{g}^{-1}\right.$ ) of Fish Held in Still Water. (See Note, page 14)

\begin{tabular}{lccccc}
\hline Source & df & ss & mss & F.Calc. & Prob. of F. \\
\hline Days & 1 & 0.0068 & 0.0068 & 4.10 & $0.96^{*}$ \\
Time Intervals & 5 & 0.0167 & 0.0033 & 2.03 & 0.92 \\
Interaction & 5 & 0.0106 & 0.0021 & 1.28 & 0.72 \\
Error & 84 & 0.1386 & 0.0017 & & \\
Total & 95 & 0.1727 & & & \\
\hline
\end{tabular}

\begin{tabular}{lccccc}
\hline Source & df & ss & mss & F.Calc. & Prob. of F. \\
\hline Days & 1 & 0.0068 & 0.0068 & 4.08 & $0.96^{*}$ \\
Light and Dark & 1 & 0.0068 & 0.0068 & 4.10 & $0.96^{*}$ \\
Interaction & 1 & 0.0065 & 0.0065 & 3.92 & 0.95 \\
Error & 92 & 0.1526 & 0.0017 & & \\
Total & 95 & 0.1727 & & & \\
\hline
\end{tabular}

Buoyancies $\left(\mathrm{mL} \cdot \mathrm{g}^{-1}\right.$ ) of $\mathrm{Fish}$ Held in $20 \mathrm{~cm} \cdot \mathrm{s}^{-1}$ Current.

\begin{tabular}{lccccc}
\hline Source & df & ss & mss & F.Calc. & Prob. of F. \\
\hline Days & 1 & 0.1166 & 0.1166 & 7.63 & $0.99 *$ \\
Time Intervals & 5 & 0.1400 & 0.0280 & 1.83 & 0.86 \\
Interaction & 5 & 0.1100 & 0.0220 & 1.44 & 0.78 \\
Error & 84 & 1.2837 & 0.0153 & & \\
Total & 95 & 1.6503 & & & \\
\hline
\end{tabular}

\begin{tabular}{lccccc}
\hline Source & df & ss & mss & F.Calc. & Prob. of F. \\
\hline Days & $I$ & 0.1166 & 0.1166 & 7.11 & $0.99 *$ \\
Light and Dark & 1 & 0.0240 & 0.0240 & 1.46 & 0.77 \\
Interaction & 1 & 0.0005 & 0.0005 & 0.03 & 0.16 \\
Error & 92 & 1.5092 & 0.0164 & & \\
Total & 95 & 1.6503 & & & \\
\hline
\end{tabular}

Standard Volumes $\left(\mathrm{mL} \cdot \mathrm{g}^{-1}\right)$ of Fish Held in still water.

\begin{tabular}{lccccc}
\hline Source & df & ss & mss & F.Calc. & Prob. of F. \\
\hline Days & 1 & 0.0009 & 0.0009 & 0.20 & 0.34 \\
Time Intervals & 5 & 0.0213 & 0.0043 & 1.01 & 0.58 \\
Interaction & 5 & 0.0373 & 0.0075 & 1.76 & 0.87 \\
Error & 84 & 0.3558 & 0.0042 & & \\
Total & 95 & 0.4153 & & & \\
\hline
\end{tabular}


APPENDIX 4 cont'd

Standard Volumes $\left(\mathrm{mL} \cdot \mathrm{g}^{-1}\right.$ ) of Fish Held in still Water.

\begin{tabular}{lccccc}
\hline Source & df & ss & mss & F.Calc. & Prob. of F. \\
\hline Days & 1 & 0.0009 & 0.0009 & 0.19 & 0.34 \\
Light and Dark & 1 & 0.0058 & 0.0058 & 1.32 & 0.75 \\
Interaction & 1 & 0.0032 & 0.0032 & 0.74 & 0.60 \\
Error & 92 & 0.4054 & 0.0044 & & \\
Total & 95 & 0.4153 & & & \\
\hline
\end{tabular}

Standard Volumes $\left(\mathrm{mL} \cdot \mathrm{g}^{-1}\right)$ of $\mathrm{Fish}$ Held in $20 \mathrm{~cm} \cdot \mathrm{s}^{-1}$ Current.

\begin{tabular}{lccccc}
\hline Source & df & ss & mss & F.Calc. & Prob. of F. \\
\hline Days & 1 & 0.2158 & 0.2158 & 11.56 & $1.00^{*}$ \\
Time Intervals & 5 & 0.2916 & 0.0583 & 3.12 & $0.99 *$ \\
Interaction & 5 & 0.1716 & 0.0343 & 1.84 & 0.89 \\
Error & 84 & 1.5675 & 0.0187 & & \\
Total & 95 & 2.2466 & & & \\
\hline
\end{tabular}

\begin{tabular}{lccccc}
\hline Source & df & ss & mss & F.Calc. & Prob. of F. \\
\hline Days & 1 & 0.2158 & 0.2158 & 9.89 & $1.00 *$ \\
Light and Dark & 1 & 0.0238 & 0.0238 & 1.09 & 0.70 \\
Interaction 6 & 1 & 0.0001 & 0.0001 & 0.005 & 0.10 \\
Error & 92 & 2.0069 & 0.0218 & & \\
Total & 95 & 2.2466 & & & \\
\hline
\end{tabular}

Internal Pressures $\left(\mathrm{Pa} \cdot 10^{5}\right)$ of Fish Held in Still water.

\begin{tabular}{lccccc}
\hline Source & df & ss & mss & F.Calc. & Prob. of F. \\
\hline Days & 1 & 0.0034 & 0.0034 & 1.13 & 0.71 \\
Time Intervals & 5 & 0.0089 & 0.0018 & 0.60 & 0.30 \\
Interaction & 5 & 0.0170 & 0.0034 & 1.14 & 0.66 \\
Error & 84 & 0.2500 & 0.0030 & & \\
Total & 95 & 0.2793 & & & \\
\hline
\end{tabular}

\begin{tabular}{lccccc}
\hline Source & df & ss & mss & F.Calc. & Prob. of F. \\
\hline Days & 1 & 0.0034 & 0.0034 & 1.12 & 0.71 \\
Light and Dark & 1 & 0.0002 & 0.0002 & 0.07 & 0.22 \\
Interaction & 1 & 0.0009 & 0.0009 & 0.29 & 0.44 \\
Error & 92 & 0.2749 & 0.0030 & & \\
Total & 95 & 0.2793 & & & \\
\hline
\end{tabular}


APPENDIX 4 cont'd

Internal Pressure $\left(\mathrm{Pa} \cdot 10^{5}\right)$ of $\mathrm{Fish}$ Held in $20 \mathrm{~cm} \cdot \mathrm{s}^{-1}$ Current.

\begin{tabular}{lccccc}
\hline Source & df & ss & mss & F. Calc. & Prob. of F. \\
\hline Days & 1 & 0.0103 & 0.0103 & 1.78 & 0.82 \\
Time Intervals & 5 & 0.0489 & 0.0098 & 1.70 & 0.86 \\
Interaction & 5 & 0.0430 & 0.0086 & 1.49 & 0.80 \\
Error & 84 & 0.4842 & 0.0058 & & \\
Total & 95 & 0.5864 & & & \\
\hline
\end{tabular}

\begin{tabular}{lccccc}
\hline Source & df & ss & mss & F.Calc. & Prob. of F. \\
\hline Days & 1 & 0.0103 & 0.0103 & 1.65 & 0.30 \\
Light and Dark & 1 & 0.0020 & 0.0020 & 0.33 & 0.42 \\
Interaction & 1 & 0.0005 & 0.0005 & 0.09 & 0.24 \\
Error & 92 & 0.5735 & 0.0062 & & \\
Total & 95 & 0.5864 & & & \\
\hline
\end{tabular}




\section{APPENDIX 5}

Two-Way Analyses of Variance: (See Note, page 14)

Effects on Buoyancy $\left(\mathrm{mL}^{\circ} \mathrm{g}^{-1}\right)$ of Long Term Exposure to 10, 20, and $30 \mathrm{~cm} \cdot \mathrm{s}^{-1}$ current at $21^{\circ} \mathrm{C}$.

\begin{tabular}{lrcccc}
\hline Source & df & ss & mss & F.Calc. & F.Crit. \\
\hline Water Velocity & 2 & 0.0378 & 0.0189 & 1.56 & 3.01 \\
Time & 7 & 0.6245 & 0.0892 & $7.36 *$ & 2.01 \\
Interaction & 14 & 0.2781 & 0.0199 & 1.64 & 1.69 \\
Error & 168 & 2.0378 & 0.0121 & & \\
Total & 191 & 2.9782 & & & \\
\hline
\end{tabular}

Effects on Standard Volume $\left(\mathrm{mL} \cdot \mathrm{g}^{-1}\right)$ of Long Term Exposure to 10, 20, and $30 \mathrm{~cm} \cdot \mathrm{s}^{-1}$ Current at $21^{\circ} \mathrm{C}$.

\begin{tabular}{lrrccc}
\hline Source & df & ss & mss & F.Calc. & F.Crit. \\
\hline Water Velocity & 2 & 0.1009 & 0.0505 & 3.01 & 3.01 \\
Time & 7 & 0.7638 & 0.1091 & $6.52 *$ & 2.01 \\
Interaction & 14 & 0.5030 & 0.0359 & $2.15 *$ & 1.69 \\
Error & 168 & 2.8123 & 0.0167 & & \\
Total & 191 & 4.1801 & & & \\
\hline
\end{tabular}

Effects on Internal Pressure $\left(\mathrm{Pa} \cdot 10^{5}\right)$ of Long Term Exposure to 10 , 20 , and $30 \mathrm{~cm} \cdot \mathrm{s}^{-1}$ Current at $21^{\circ} \mathrm{C}$.

\begin{tabular}{lrrccc}
\hline Source & df & ss & mss & F.Calc. & F.Crit. \\
\hline Water Velocity & 2 & 0.0229 & 0.0155 & 1.50 & 3.01 \\
Time & 7 & 0.0501 & 0.0072 & 0.94 & 2.01 \\
Interaction & 14 & 0.2569 & 0.0184 & $2.41^{*}$ & 1.69 \\
Error & 168 & 1.2810 & 0.0076 & & \\
Total & 191 & 1.6110 & & & \\
\hline
\end{tabular}

Effects on Buoyancy $\left(\mathrm{mL} \cdot \mathrm{g}^{-1}\right)$ of Long Term Exposure to 10,20 , and $30 \mathrm{~cm} \cdot \mathrm{s}^{-1}$ current at $30^{\circ} \mathrm{C}$.

\begin{tabular}{lrcccc}
\hline Source & df & ss & mss & F.Calc. & F.Crit. \\
\hline Water Velocity & 2 & 0.2543 & 0.1271 & $10.56 *$ & 3.01 \\
Time & 7 & 0.0641 & 0.0092 & 0.76 & 2.01 \\
Interaction & 14 & 0.4421 & 0.0316 & $2.62 *$ & 1.69 \\
Error & 168 & 2.0225 & 0.0120 & & \\
Total & 191 & 2.7830 & & & \\
\hline
\end{tabular}


APPENDIX 5 cont'd

Effects on Standard Volume $\left(\mathrm{mL} \cdot \mathrm{g}^{-1}\right)$ of Long Term Exposure to 10, 20, and $30 \mathrm{~cm} \cdot \mathrm{s}^{-1}$ Current at $30^{\circ} \mathrm{C}$.

\begin{tabular}{lrrrrc}
\hline Source & df & ss & mss & F.Calc. & F. Crit. \\
\hline Water Velocity & 2 & 0.2615 & 0.1308 & $10.10^{*}$ & 3.01 \\
Time & 7 & 0.0437 & 0.0062 & 0.48 & 2.01 \\
Interaction & 14 & 0.4893 & 0.0350 & $2.70^{*}$ & 1.69 \\
Error & 168 & 2.1756 & 0.0129 & & \\
Total & 191 & 2.9701 & & & \\
\hline
\end{tabular}

Effects on Internal Pressure $\left(\mathrm{Pa} \cdot 10^{5}\right)$ of Long Term Exposure to 10, 20, and $30 \mathrm{~cm} \cdot \mathrm{s}^{-1}$ Current at $30^{\circ} \mathrm{C}$.

\begin{tabular}{lrrrrl}
\hline Source & df & ss & mss & F.Calc. & F. Crit. \\
\hline Water Velocity & 2 & 0.0265 & 0.0133 & 1.38 & 3.01 \\
Time & 7 & 0.1736 & 0.0248 & $2.58 *$ & 2.01 \\
Interaction & 14 & 0.1218 & 0.0087 & 0.91 & 1.69 \\
Error & 168 & 1.6118 & 0.0096 & & \\
Total & 191 & 1.9337 & & & \\
\hline
\end{tabular}

Effects on Buoyancy $\left(\mathrm{mL} \cdot \mathrm{g}^{-1}\right)$ of Long Term Exposure to $20 \mathrm{~cm} \cdot \mathrm{s}^{-1}$ Current at $5,11,21,26$, and $30^{\circ} \mathrm{C}$.

\begin{tabular}{lrrrrr}
\hline Source & df & ss & mss & F.Calc. & F. Crit. \\
\hline Temperature & 4 & 0.8893 & 0.2223 & $16.46^{*}$ & 2.37 \\
Time & 7 & 0.3344 & 0.0478 & $3.54^{*}$ & 2.01 \\
Interaction & 28 & 0.5884 & 0.0210 & $1.56^{*}$ & 1.48 \\
Error & 280 & 3.7824 & 0.0135 & & \\
Total & 319 & 5.5946 & & & \\
\hline
\end{tabular}

Effects on Standard Volume $\left(\mathrm{mL} \cdot \mathrm{g}^{-1}\right)$ of Long Term Exposure to $20 \mathrm{~cm} \cdot \mathrm{s}^{-1}$ current at $5,11,21,26$, and $30^{\circ} \mathrm{C}$.

\begin{tabular}{lrrrrr}
\hline Source & df & ss & mss & F.Calc. & F. Crit. \\
\hline Temperature & 4 & 0.7095 & 0.1774 & $10.11^{*}$ & 2.37 \\
Time & 7 & 0.4481 & 0.0640 & $3.65^{*}$ & 2.01 \\
Interaction & 28 & 0.9206 & 0.0329 & $1.87^{*}$ & 1.48 \\
Error & 280 & 4.9109 & 0.0175 & & \\
Total & 319 & 6.9891 & & & \\
\hline
\end{tabular}


APPENDIX 5 cont'd

Effects on Internal Pressure $\left(\mathrm{Pa} \cdot 10^{5}\right)$ of Long Term Exposure to $20 \mathrm{~cm} \cdot \mathrm{s}^{-1}$ Current at $5,11,21,26$, and $30^{\circ} \mathrm{C}$.

\begin{tabular}{lrrccc}
\hline Source & df & ss & mss & F.Calc. & F. Crit. \\
\hline Temperature & 4 & 0.1823 & 0.0456 & $4.35 *$ & 2.37 \\
Time & 7 & 0.1584 & 0.0226 & $2.16 *$ & 2.01 \\
Interaction & 28 & 0.7897 & 0.0282 & $2.69 *$ & 1.48 \\
Error & 280 & 2.9324 & 0.0105 & & \\
Total & 319 & 4.0628 & & & \\
\hline
\end{tabular}

Effects on Buoyancy (mL. $\mathrm{g}^{-1}$ ) of Long Term Exposure, Between 10 and 42 days, to 10,20 and $30 \mathrm{~cm} \cdot \mathrm{s}^{-1}$ Current at $30^{\circ} \mathrm{C}$.

\begin{tabular}{lrcccc}
\hline Source & df & ss & mss & F.Calc. & F. Crit. \\
\hline Water Velocity & 2 & 0.3873 & 0.1936 & $18.57 *$ & 3.09 \\
Time & 4 & 0.0282 & 0.0071 & 0.68 & 2.46 \\
Interaction & 8 & 0.1695 & 0.0212 & 2.03 & 2.03 \\
Error & 105 & 1.0952 & 0.0104 & & \\
Total & 119 & 1.6802 & & & \\
\hline
\end{tabular}

Effects on Internal Pressure $\left(\mathrm{Pa} \cdot 10^{5}\right)$ of Long Term Exposure Between 10 and 42 days to 10,20 , and $30 \mathrm{~cm} \cdot \mathrm{s}^{-1}$ Current at $30^{\circ} \mathrm{C}$.

\begin{tabular}{lrcccc}
\hline Source & df & ss & mss & F.Calc. & F. Crit. \\
\hline Water Velocity & 2 & 0.0160 & 0.0080 & 0.96 & 3.09 \\
Days & 4 & 0.0284 & 0.0071 & 0.85 & 2.46 \\
Interaction & 8 & 0.0862 & 0.0108 & 1.29 & 2.03 \\
Error & 105 & 0.8752 & 0.0083 & & \\
Total & 119 & 1.0058 & & & \\
\hline
\end{tabular}

Effects on Standard Volume $\left(\mathrm{mL} \cdot \mathrm{g}^{-1}\right)$ of Long Term Exposure Between 10 and 42 Days to 10,20 , and $30 \mathrm{~cm} \cdot \mathrm{s}^{-1}$ Current at $30^{\circ} \mathrm{C}$.

\begin{tabular}{lrcccc}
\hline Source & df & ss & mss & F.Calc. & F. Crit. \\
\hline Water Velocity & 2 & 0.4070 & 0.2035 & $16.70 *$ & 3.09 \\
Days & 4 & 0.0391 & 0.0098 & 0.80 & 2.46 \\
Interaction & 8 & 0.2307 & 0.0288 & $2.37 *$ & 2.03 \\
Error & 105 & 1.2791 & 0.0122 & & \\
Total & 119 & 1.9559 & & & \\
\hline
\end{tabular}


APPENDIX 5 cont'd

Regression Analyses: (See Note, page 14)

Buoyancy $\left(\mathrm{mL} \cdot \mathrm{g}^{-1}\right)$ vs. Water Velocity $\left(\mathrm{cm} \cdot \mathrm{s}^{-1}\right)$ at $30^{\circ} \mathrm{C}$ Between 10 and 42 days in Current.

\begin{tabular}{lrrccc}
\hline Source & df & ss & mss & F. Calc. & F. Crit. \\
\hline Total & 119 & 1.6802 & 0.0141 & & \\
Regression & 1 & 0.3868 & 0.3868 & $35.29 *$ & 3.92 \\
Residual & 118 & 1.2934 & 0.0110 & & \\
Lack of Fit & 1 & 0.0005 & 0.0005 & 0.045 & 3.92 \\
Pure Error & 117 & 1.2929 & 0.0111 & & \\
\hline
\end{tabular}

Regression Equation: $y=0.8075-0.0070 x, r^{2}=0.230$

Standard Volume $\left(\mathrm{ml} \cdot \mathrm{g}^{-1}\right)$ vs. Water Velocity $\left(\mathrm{cm} \cdot \mathrm{s}^{-1}\right)$ at $30^{\circ} \mathrm{C}$ Between 10 and 42 Days in Current.

\begin{tabular}{lrcccc}
\hline Source & df & ss & mss & F. Calc. & F. Crit. \\
\hline Total & 119 & 1.9559 & 0.0164 & & \\
Regression & 1 & 0.4042 & 0.4042 & $30.74 *$ & 3.92 \\
Residual & 118 & 1.5517 & 0.0132 & & 3.92 \\
Lack of Fit & 1 & 0.0028 & 0.0028 & 0.211 & 3 \\
Pure Error & 117 & 1.5489 & 0.0132 & & \\
Regression Equation: $y=0.8889-0.0071 \times, r^{2}=0.207$ &
\end{tabular}

Internal Pressure $\left(\mathrm{Pa} \cdot 10^{5}\right)$ vs. Water Velocity $\left(\mathrm{cm} \cdot \mathrm{s}^{-1}\right)$ at $30^{\circ} \mathrm{C}$ Between 10 and 42 Days in Current.

\begin{tabular}{|c|c|c|c|c|c|}
\hline Source & $d f$ & ss & mss & F.Calc. & F.Crit \\
\hline Total & 119 & 1.0058 & 0.0084 & & \\
\hline Regression & 1 & 0.0039 & 0.0039 & 0.45 & 3.92 \\
\hline Residual & 118 & 1.0020 & 0.0085 & & \\
\hline Lack of Fit & 1 & 0.0121 & 0.0121 & 1.43 & 3.92 \\
\hline Pure Error & $11 \overline{7}$ & 0.9898 & 0.0085 & & \\
\hline
\end{tabular}


APPENDIX 5 cont'd.

Comparisons of the Mean Internal Pressure and Variance Measurements Between the First Four Measurements in Current $(2,4,7,10 \mathrm{~d})$ and the Last Four Measurements $(18,26,34,42 \mathrm{~d})$.

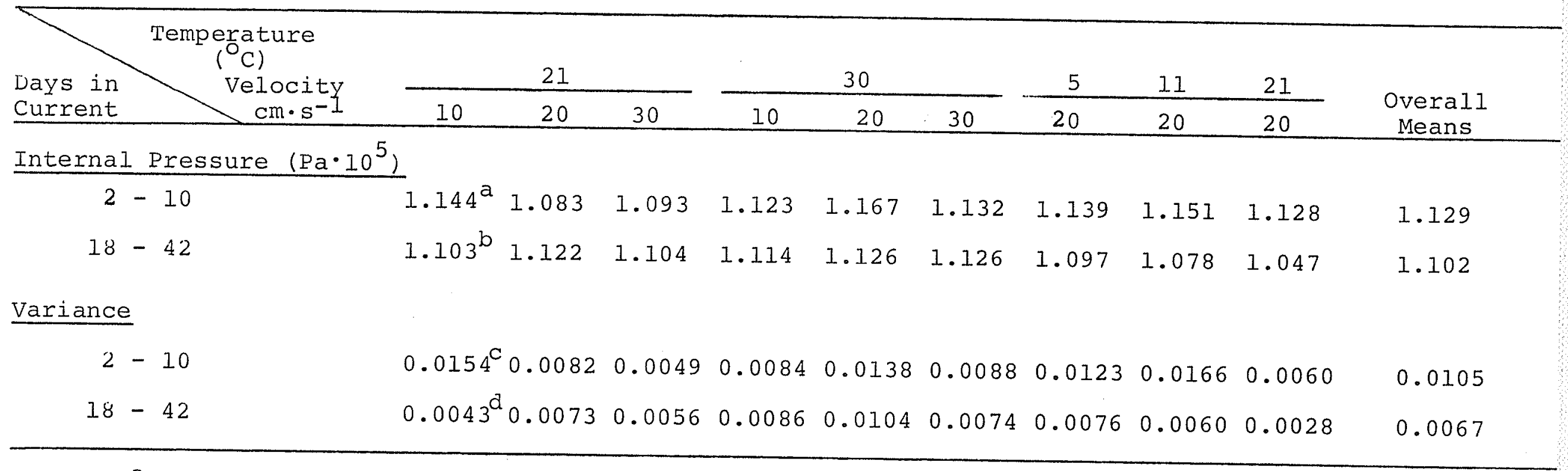
mean $(n=32)$ of internal pressure measurements taken after $2,4,7$, and 10
days in $10 \mathrm{~cm} \cdot \mathrm{s}^{-1}$ current at $21^{\circ} \mathrm{C}$.

b as above except $18,26,34$, and 42 days.

$C$ mean $(n=4)$ variance of the mean internal pressure $(n=8)$ after $2,4,7$, and 10 days in $10 \mathrm{~cm} \cdot \mathrm{s}^{-1}$ current at $21^{\circ} \mathrm{C}$.

as above except $18,26,34$, and 42 days. 


\section{APPENDIX 6}

Buoyancy, Standard Volume, and Internal Pressure Response to Constant or Increasing Water Velocity and Constant or Increasing Water Temperature.

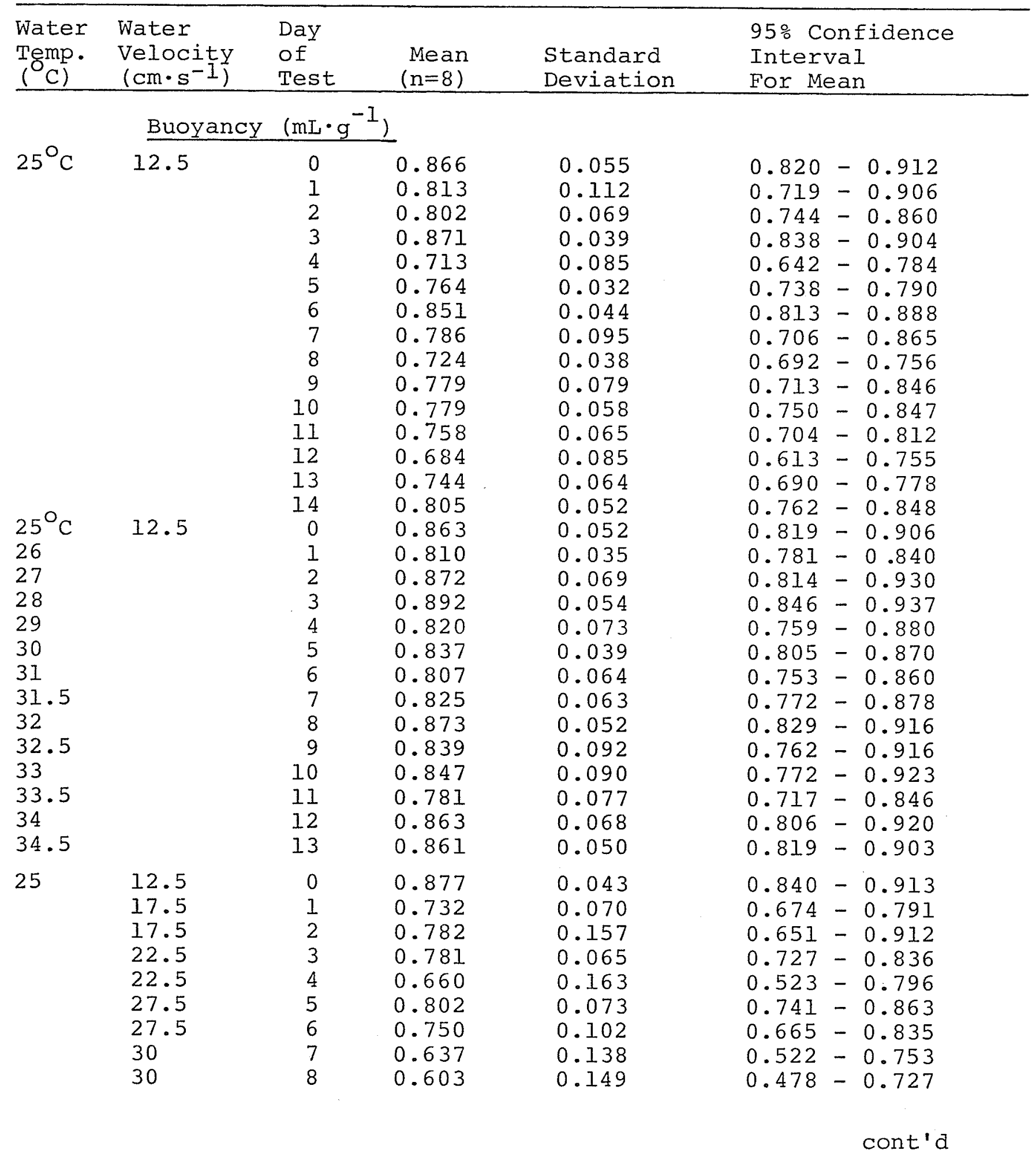


APPENDIX 6 cont'd

\begin{tabular}{|c|c|c|c|c|c|c|}
\hline $\begin{array}{l}\text { Water } \\
\text { Temp. } \\
\left({ }^{\mathrm{C}}\right)\end{array}$ & $\begin{array}{l}\text { Water } \\
\text { Velocity } \\
\left(\mathrm{cm} \cdot \mathrm{s}^{-1}\right)\end{array}$ & $\begin{array}{l}\text { Day } \\
\text { of } \\
\text { Test }\end{array}$ & $\begin{array}{l}\text { Mean } \\
(n=8)\end{array}$ & $\begin{array}{l}\text { Standard } \\
\text { Deviation }\end{array}$ & \multicolumn{2}{|c|}{$\begin{array}{l}\text { 95\% Confidence } \\
\text { Interval } \\
\text { For Mean }\end{array}$} \\
\hline 25 & $\begin{array}{l}32.5 \\
32.5 \\
35 \\
35 \\
35\end{array}$ & $\begin{array}{r}9 \\
10 \\
11 \\
12 \\
13\end{array}$ & $\begin{array}{l}0.511 \\
0.569 \\
0.566 \\
0.468 \\
0.552\end{array}$ & $\begin{array}{l}0.130 \\
0.115 \\
0.124 \\
0.105 \\
0.106\end{array}$ & $\begin{array}{l}0.403 \\
0.473 \\
0.463 \\
0.380 \\
0.464\end{array}$ & $\begin{array}{l}-0.620 \\
-0.666 \\
-0.670 \\
-0.556 \\
-0.640\end{array}$ \\
\hline $\begin{array}{l}25 \\
26 \\
27 \\
28 \\
29 \\
30 \\
31 \\
31.5 \\
32 \\
32.5 \\
33 \\
33.5 \\
34 \\
34.5 \\
35\end{array}$ & $\begin{array}{l}12.5 \\
17.5 \\
17.5 \\
22.5 \\
22.5 \\
27.5 \\
27.5 \\
30 \\
30 \\
32.5 \\
32.5 \\
35 \\
35 \\
35 \\
35\end{array}$ & $\begin{array}{l}0 \\
1 \\
2 \\
3 \\
4 \\
5 \\
6 \\
7 \\
8 \\
9 \\
10 \\
11 \\
12 \\
13 \\
14\end{array}$ & $\begin{array}{l}0.804 \\
0.800 \\
0.849 \\
0.889 \\
0.805 \\
0.788 \\
0.826 \\
0.809 \\
0.829 \\
0.762 \\
0.764 \\
0.841 \\
0.798 \\
0.855 \\
0.941\end{array}$ & $\begin{array}{l}0.086 \\
0.094 \\
0.069 \\
0.044 \\
0.117 \\
0.080 \\
0.036 \\
0.082 \\
0.069 \\
0.076 \\
0.090 \\
0.061 \\
0.091 \\
0.088 \\
0.109\end{array}$ & $\begin{array}{l}0.732 \\
0.716 \\
0.791 \\
0.852 \\
0.768 \\
0.721 \\
0.796 \\
0.741 \\
0.771 \\
0.669 \\
0.689 \\
0.790 \\
0.723 \\
0.781 \\
0.851\end{array}$ & $\begin{array}{l}-0.876 \\
-0.883 \\
-0.907 \\
-0.926 \\
-0.903 \\
-0.355 \\
-0.856 \\
-0.877 \\
-0.887 \\
-0.826 \\
-0.840 \\
-0.893 \\
-0.874 \\
-0.930 \\
-1.033\end{array}$ \\
\hline & Standard & Vol ume & $\left(\mathrm{mL} \cdot \mathrm{g}^{-1}\right)$ & & & \\
\hline 25 & 25 & $\begin{array}{r}0 \\
1 \\
2 \\
3 \\
4 \\
5 \\
6 \\
7 \\
8 \\
9 \\
10 \\
11 \\
12 \\
13 \\
14\end{array}$ & $\begin{array}{l}0.940 \\
0.896 \\
0.860 \\
0.918 \\
0.723 \\
0.802 \\
0.933 \\
0.812 \\
0.795 \\
0.875 \\
0.836 \\
0.805 \\
0.694 \\
0.837 \\
0.877\end{array}$ & $\begin{array}{l}0.086 \\
0.094 \\
0.061 \\
0.017 \\
0.130 \\
0.045 \\
0.049 \\
0.096 \\
0.051 \\
0.112 \\
0.087 \\
0.074 \\
0.114 \\
0.084 \\
0.078\end{array}$ & $\begin{array}{l}0.868 \\
0.818 \\
0.808 \\
0.904 \\
0.644 \\
0.764 \\
0.892 \\
0.732 \\
0.752 \\
0.781 \\
0.763 \\
0.744 \\
0.603 \\
0.766 \\
0.812\end{array}$ & $\begin{array}{l}-1.013 \\
-0.974 \\
-0.911 \\
-0.932 \\
-0.861 \\
-0.839 \\
-0.975 \\
-0.892 \\
-0.837 \\
-0.968 \\
-0.909 \\
-0.867 \\
-0.794 \\
-0.907 \\
-0.943\end{array}$ \\
\hline $\begin{array}{l}25 \\
26 \\
27 \\
28 \\
29 \\
30 \\
31 \\
31.5\end{array}$ & 25 & $\begin{array}{l}0 \\
1 \\
2 \\
3 \\
4 \\
5 \\
6 \\
7\end{array}$ & $\begin{array}{l}0.925 \\
0.872 \\
0.946 \\
0.957 \\
0.865 \\
0.900 \\
0.887 \\
0.912\end{array}$ & $\begin{array}{l}0.074 \\
0.054 \\
0.063 \\
0.062 \\
0.082 \\
0.044 \\
0.064 \\
0.079\end{array}$ & $\begin{array}{l}0.862 \\
0.826 \\
0.894 \\
0.906 \\
0.796 \\
0.864 \\
0.834 \\
0.846\end{array}$ & $\begin{array}{l}-0.987 \\
-\quad 0.917 \\
-0.999 \\
-\quad 1.009 \\
-0.933 \\
-0.937 \\
-0.941 \\
-0.978\end{array}$ \\
\hline
\end{tabular}


APPENDIX 6 cont'd

\begin{tabular}{|c|c|c|c|c|c|c|}
\hline $\begin{array}{l}\text { Water } \\
\text { T'emp. } \\
\text { ( } \mathrm{C}) \\
\end{array}$ & $\begin{array}{l}\text { Water } \\
\text { Velocity } \\
\left(\mathrm{cm} \cdot \mathrm{s}^{-1}\right)\end{array}$ & $\begin{array}{l}\text { Day } \\
\text { of } \\
\text { Test }\end{array}$ & $\begin{array}{c}\text { Mean } \\
(n=8) \\
\end{array}$ & $\begin{array}{l}\text { Standard } \\
\text { Deviation }\end{array}$ & $\begin{array}{l}95 \% \mathrm{Co} \\
\text { Interv } \\
\text { For Me }\end{array}$ & $\begin{array}{l}\text { onfidence } \\
\operatorname{ral} \\
\operatorname{ean} \\
\end{array}$ \\
\hline $\begin{array}{l}32 \\
32.5 \\
33 \\
33.5 \\
34 \\
34.5\end{array}$ & & $\begin{array}{r}8 \\
9 \\
10 \\
11 \\
12 \\
13\end{array}$ & $\begin{array}{l}0.932 \\
0.982 \\
0.901 \\
0.901 \\
0.998 \\
0.924\end{array}$ & $\begin{array}{l}0.083 \\
0.169 \\
0.110 \\
0.090 \\
0.113 \\
0.062\end{array}$ & $\begin{array}{l}0.862 \\
0.841 \\
0.809 \\
0.826 \\
0.903 \\
0.873\end{array}$ & $\begin{array}{l}-1.002 \\
-1.123 \\
-0.993 \\
-0.976 \\
-1.092 \\
-0.976\end{array}$ \\
\hline 25 & $\begin{array}{l}12.5 \\
17.5 \\
17.5 \\
22.5 \\
22.5 \\
27.5 \\
27.5 \\
30 \\
30 \\
32.5 \\
32.5 \\
35 \\
35 \\
35\end{array}$ & $\begin{array}{r}0 \\
1 \\
2 \\
3 \\
4 \\
5 \\
6 \\
7 \\
8 \\
9 \\
10 \\
11 \\
12 \\
13\end{array}$ & $\begin{array}{l}0.919 \\
0.778 \\
0.848 \\
0.848 \\
0.737 \\
0.825 \\
0.820 \\
0.690 \\
0.606 \\
0.596 \\
0.674 \\
0.633 \\
0.598 \\
0.574\end{array}$ & $\begin{array}{l}0.055 \\
0.080 \\
0.183 \\
0.066 \\
0.144 \\
0.080 \\
0.127 \\
0.149 \\
0.150 \\
0.139 \\
0.145 \\
0.139 \\
0.130 \\
0.105\end{array}$ & $\begin{array}{l}0.873 \\
0.712 \\
0.695 \\
0.793 \\
0.617 \\
0.759 \\
0.715 \\
0.565 \\
0.480 \\
0.480 \\
0.554 \\
0.517 \\
0.490 \\
0.485\end{array}$ & $\begin{array}{l}-0.964 \\
-0.845 \\
-1.002 \\
-0.903 \\
-0.857 \\
-0.892 \\
-0.926 \\
-0.815 \\
-0.732 \\
-0.712 \\
-0.795 \\
-0.749 \\
-0.707 \\
-0.662\end{array}$ \\
\hline $\begin{array}{l}25 \\
26 \\
27 \\
28 \\
29 \\
30 \\
31 \\
31.5 \\
32 \\
32.5 \\
33 \\
33.5 \\
34 \\
34.5 \\
35\end{array}$ & $\begin{array}{l}12.5 \\
17.5 \\
17.5 \\
22.5 \\
22.5 \\
27.5 \\
27.5 \\
30 \\
30 \\
32.5 \\
32.5 \\
35 \\
35 \\
35 \\
35\end{array}$ & $\begin{array}{r}0 \\
1 \\
2 \\
3 \\
4 \\
5 \\
6 \\
7 \\
8 \\
9 \\
10 \\
11 \\
12 \\
13 \\
14\end{array}$ & $\begin{array}{l}0.832 \\
0.848 \\
0.881 \\
0.937 \\
0.891 \\
0.822 \\
0.897 \\
0.830 \\
0.867 \\
0.844 \\
0.850 \\
0.979 \\
0.898 \\
0.999 \\
0.985\end{array}$ & $\begin{array}{l}0.105 \\
0.108 \\
0.068 \\
0.056 \\
0.132 \\
0.085 \\
0.079 \\
0.095 \\
0.071 \\
0.102 \\
0.091 \\
0.097 \\
0.130 \\
0.094 \\
0.084\end{array}$ & $\begin{array}{l}0.744 \\
0.757 \\
0.825 \\
0.890 \\
0.781 \\
0.751 \\
0.831 \\
0.751 \\
0.807 \\
0.759 \\
0.774 \\
0.897 \\
0.789 \\
0.921 \\
0.915\end{array}$ & $\begin{array}{l}-0.920 \\
-0.939 \\
-0.938 \\
-0.984 \\
-1.001 \\
-0.893 \\
-0.963 \\
-0.909 \\
-0.967 \\
-0.930 \\
-0.926 \\
-1.060 \\
-1.007 \\
-1.078 \\
-1.056\end{array}$ \\
\hline & Internal & cess & $(\mathrm{Pa} \cdot]$ & & & \\
\hline 25 & 12.5 & $\begin{array}{l}0 \\
1 \\
2 \\
3 \\
4 \\
5 \\
6\end{array}$ & $\begin{array}{l}1.086 \\
1.109 \\
1.073 \\
1.056 \\
1.049 \\
1.049 \\
1.098\end{array}$ & $\begin{array}{l}0.076 \\
0.073 \\
0.026 \\
0.039 \\
0.072 \\
0.026 \\
0.031\end{array}$ & $\begin{array}{l}1.022 \\
1.048 \\
1.052 \\
1.023 \\
0.989 \\
1.028 \\
1.071\end{array}$ & $\begin{array}{l}-1.150 \\
-1.170 \\
-1.095 \\
-1.0888 \\
-1.109 \\
-1.071 \\
-1.124\end{array}$ \\
\hline
\end{tabular}


APPENDIX 6 cont'd

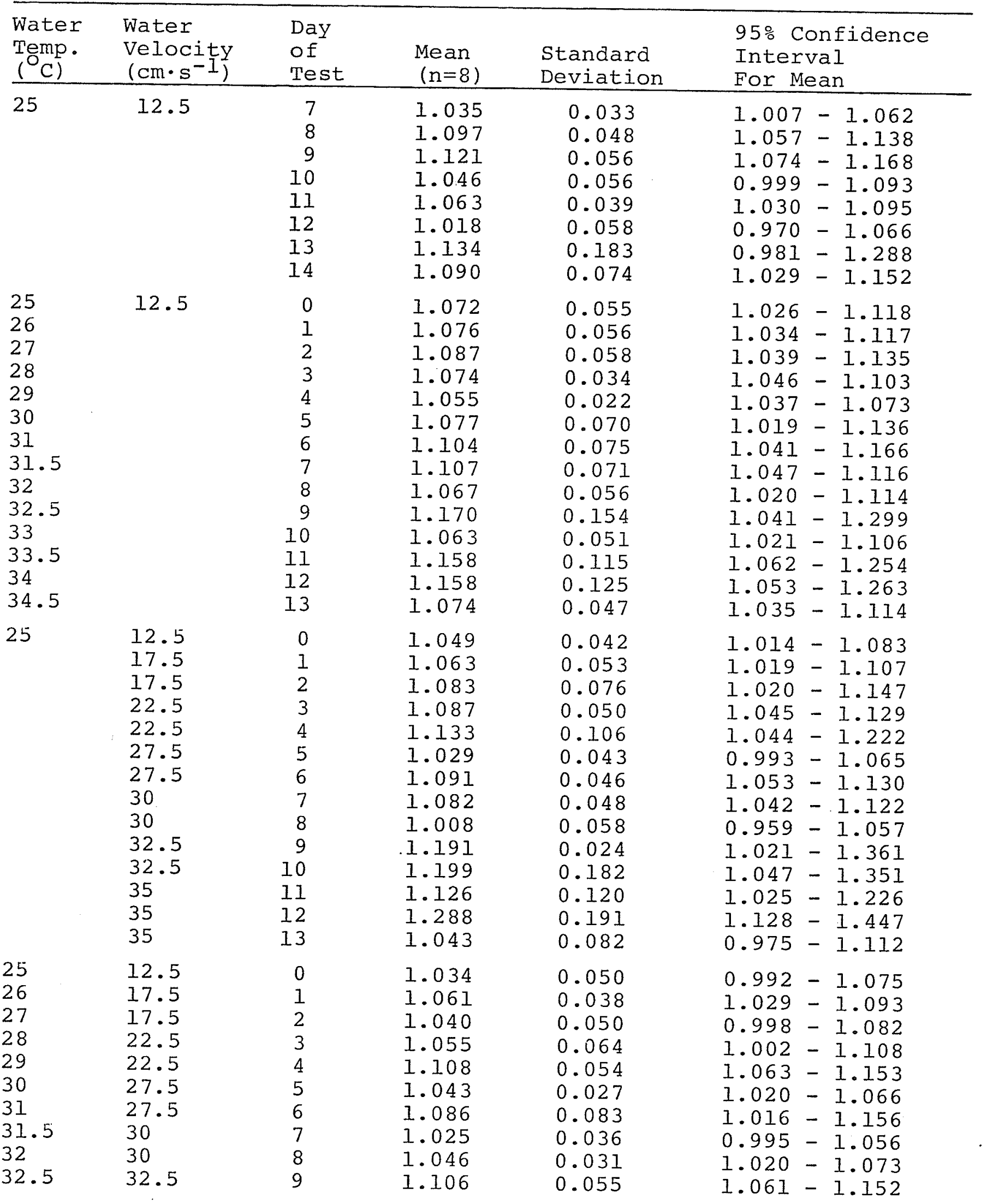

cont'd 
APPENDIX 6 cont'd

\begin{tabular}{llllll}
\hline $\begin{array}{l}\text { Water } \\
\text { Temp. } \\
\left({ }^{\mathrm{C})}\right)\end{array}$ & $\begin{array}{l}\text { Water } \\
\text { Velocity } \\
\left(\mathrm{cm} \cdot \mathrm{s}^{-1}\right)\end{array}$ & $\begin{array}{l}\text { Day } \\
\text { of } \\
\text { Test }\end{array}$ & $\begin{array}{l}\text { Mean } \\
(\mathrm{n}=8)\end{array}$ & $\begin{array}{l}\text { Standard } \\
\text { Deviation }\end{array}$ & $\begin{array}{l}\text { 95\% Confidence } \\
\text { Interval } \\
\text { For Mean }\end{array}$ \\
\hline 33 & 32.5 & 10 & 1.116 & 0.087 & $1.043-1.188$ \\
33.5 & 35 & 11 & 1.163 & 0.075 & $1.101-1.226$ \\
34 & 35 & 12 & 1.123 & 0.094 & $1.044-1.201$ \\
34.5 & 35 & 13 & 1.172 & 0.092 & $1.095-1.249$ \\
35 & 35 & 14 & 1.050 & 0.051 & $1.008-1.093$ \\
\hline
\end{tabular}


APPENDIX 6 cont'd

REGRESSION ANALYSES TABLES: (See Note, page 14)

Time (d) in a Constant Water Temperature and Velocity vs. Buoyancy $\left(\mathrm{mL} \cdot \mathrm{g}^{-1}\right)$.

\begin{tabular}{lrlccc}
\hline Source & df & ss & mss & F.Calc. & F.Crit. \\
\hline Total & 119 & 0.8269 & 0.0070 & & \\
Regression & 1 & 0.0845 & 0.0845 & $13.42 *$ & 3.92 \\
Residual & 118 & 0.7424 & 0.0063 & & \\
Lack of Fit & 13 & 0.2485 & 0.0191 & $4.07 *$ & 1.84 \\
Pure Error & 105 & 0.4937 & 0.0047 & & \\
\hline Regression Equation: & $y=0.8269-0.0061 \times$ & $r^{2}=0.102$
\end{tabular}

Time (d) in a Constant Water Temperature and Velocity vs. Standard Volume $\left(\mathrm{mL} \cdot \mathrm{g}^{-1}\right)$.

\begin{tabular}{lrlllc}
\hline Source & df & ss & mss & F.Calc. & F.Crit. \\
\hline Total & 119 & 1.2777 & 0.0105 & & \\
Regression & 1 & 0.0923 & 0.0923 & $9.42 *$ & 3.92 \\
Residual & 118 & 1.1554 & 0.0098 & & 1.84 \\
Lack of Fit & 13 & 0.4205 & 0.0324 & $4.62 *$ & \\
Pure Error & 105 & 0.7350 & 0.0070 & & \\
\hline Regression Equation: & $y=0.8874-0.0064 \times$ & $r^{2}=0.074$
\end{tabular}

Time (d) in a Constant Water Temperature and Velocity vs. Internal Pressure $\left(\mathrm{Pa} \cdot 10^{5}\right)$.

\begin{tabular}{lrllll}
\hline Source & df & ss & mss & F.Calc. & F.Crit. \\
\hline Total & 119 & 0.6431 & 0.0054 & & \\
Regression & 1 & 0.0001 & 0.0001 & 0.02 & 3.92 \\
Residual & 118 & 0.6430 & 0.0054 & & 1.84 \\
Lack of Fit & 13 & 0.1260 & 0.0097 & $1.97^{*}$ & 1.0049 \\
Pure Error & 105 & 0.5170 & 0.004 & & \\
\hline Regression Equation: & $y=1.0733+0.0002 \times$ & $r^{2}=0.0002$
\end{tabular}


Time (d) in Increasing Water Temperature and Constant Velocity
vs. Buoyancy $\left(\mathrm{mL} \cdot \mathrm{g}^{-1}\right)$.

\begin{tabular}{lrcccc}
\hline Source & df & ss & mss & F.Calc. & F.Crit. \\
\hline Total & 111 & 0.5127 & 0.0046 & & \\
Regression & 1 & 0.0011 & 0.0011 & 0.23 & 3.94 \\
Residual & 110 & 0.5116 & 0.0046 & & 2.30 \\
Lack of Fit & 12 & 0.0980 & 0.0082 & 1.93 & 2.0042 \\
Pure Error & 98 & 0.4136 & 0.004 & \\
\hline
\end{tabular}

Regression Equation: $y=0.8470-0.0008 x, r^{2}=0.002$ Time (d) in Increasing Water Temperature and Constant Velocity
vs. Standard Volume ( $\left.\mathrm{mL} \cdot \mathrm{g}^{-1}\right)$.

\begin{tabular}{lrrccc}
\hline Source & df & ss & mss & F.Calc. & F.Crit. \\
\hline Total & 111 & 0.9095 & 0.0082 & & \\
Regression & 1 & 0.0145 & 0.0145 & 1.78 & 3.94 \\
Residual & 110 & 0.8950 & 0.0081 & & 2.30 \\
Lack of Fit & 12 & 0.1435 & 0.0120 & 1.56 & \\
Pure Error & 98 & 0.7515 & 0.0077 & & \\
\hline
\end{tabular}

Regression Equation: $y=0.9033+0.0028, \quad r^{2}=0.016$

Time (d) in Increasing Water Temperature and Constant Velocity vs. Internal Pressure $\left(\mathrm{Pa} \cdot 10^{5}\right)$.

\begin{tabular}{lrrccc}
\hline Source & df & ss & mss & F.Calc. & F.Crit. \\
\hline Total & 111 & 0.7614 & 0.0069 & & \\
Regression & 1 & 0.0368 & 0.0368 & $5.59 *$ & 3.94 \\
Residual & 110 & 0.7246 & 0.0066 & & 2.30 \\
Lack of Fit & 12 & 0.1178 & 0.0098 & 1.59 & \\
Pure Error & 98 & 0.6068 & 0.0062 & & \\
& & & & & \\
Regression Equation: $\quad Y=1.0666+0.0045 \times \quad r^{2}=0.048$
\end{tabular}


APPENDIX 6 cont'd

Time (d) in a Constant water Ternperature and Increasing Velocity
vs. Buoyancy (mL. $\left.\mathrm{g}^{-1}\right)$.

\begin{tabular}{lrrccc}
\hline Source & df & ss & mss & F.Calc. & F.Crit. \\
\hline Total & 111 & 2.9190 & 0.0263 & & \\
Regression & 1 & 1.2665 & 1.2665 & $84.30 *$ & 3.94 \\
Residual & 110 & 1.6526 & 0.0150 & & 2.14 \\
Lack of Fit & 12 & 0.3434 & 0.0286 & 2.30 \\
Pure Error & 98 & 1.3091 & 0.0134 & &
\end{tabular}

Regression Equation: $\quad y=0.8351-0.0264 x, r^{2}=0.434$

Time (d) in a Constant Water Temperature and Increasing Velocity vs. Standard Volume $\left(\mathrm{mL} \cdot \mathrm{g}^{-1}\right)$.

\begin{tabular}{lrrrrr}
\hline Source & df & ss & ms & F.Calc. & F.Crit. \\
\hline Total & 111 & 2.9373 & 0.0265 & & \\
Regression & 1 & 1.0873 & 1.0873 & $64.65 *$ & 3.94 \\
Residual & 110 & 1.8500 & 0.0168 & & 1.52 \\
Lack of Fit & 12 & 0.9206 & 0.0242 & 2.30 \\
Pure Error & 98 & 1.5594 & 0.0159 & &
\end{tabular}

Regression Equation: $\quad y=0.8837-0.0244 x, r^{2}=0.370$ Time (d) in a Constant Water Temperature and Increasing Velocity
vs. Internal Pressure $\left(\mathrm{Pa} \cdot 10^{5}\right)$.

\begin{tabular}{lrrrrr}
\hline Source & df & ss & mss & F.Calc. & F.Crit. \\
\hline Total & 111 & 1.7716 & 0.0160 & & \\
Regression & 1 & 0.1256 & 0.1256 & $8.39 *$ & 3.94 \\
Residual & 110 & 1.6460 & 0.0150 & & $3.41 *$ \\
Lack of Fit & 12 & 0.4849 & 0.0404 & 2.30 \\
Pure Error & 98 & 1.1611 & 0.0118 & &
\end{tabular}

Regression Equation: $\quad y=1.0512-0.0082 \mathrm{x}, \mathrm{r}^{2}=0.071$ 

Time (d) in Increasing Water Temperature and Velocity vs.
Buoyancy (mL $\left.\cdot \mathrm{g}^{-1}\right)$.

\begin{tabular}{lccccc}
\hline Source & df & ss & mss & F.Calc. & F.Crit. \\
\hline Total & 119 & 0.9478 & 0.0080 & & \\
Regression & 1 & 0.0137 & 0.0137 & 1.73 & 3.92 \\
Residual & 118 & 0.9341 & 0.0079 & & \\
Lack of Fit & 13 & 0.2339 & 0.0180 & $2.70 * *$ & 1.84 \\
Pure Error & 105 & 0.7002 & 0.0067 & & \\
\hline Regression Equation: & $y=0.8067+0.0025 \times$ & $r^{2}=0.014$
\end{tabular}

Time (d) in Increasing Water Temperature and Velocity vs:
Standard Volume $\left(\mathrm{mL} \cdot \mathrm{g}^{-1}\right.$ ).

\begin{tabular}{lrcccc}
\hline Source & df & ss & mss & F.Calc. & F.Crit. \\
\hline Total & 119 & 1.3662 & 0.0115 & & \\
Regression & 1 & 0.1298 & 0.1298 & $12.39 *$ & 3.92 \\
Residual & 118 & 1.2364 & 0.0105 & & \\
Lack of Fit & 13 & 0.2519 & 0.0194 & $2.07 *$ & 1.84 \\
Pure Error & 105 & 0.9845 & 0.0094 & &
\end{tabular}

Regression Equation: $\quad y=0.8516+0.0076 x \quad, \quad r^{2}=0.095$

Time (d) in Increasing Water Temperature and Velocity vs. Internal Pressure $\left(\mathrm{Pa} \cdot 10^{5}\right)$.

\begin{tabular}{lrcccc}
\hline Source & df & ss & mss & F.Calc. & F.Crit. \\
\hline Total & 119 & 0.6528 & 0.0055 & & \\
Regression & $I$ & 0.0878 & 0.0878 & $18.35 *$ & 3.92 \\
Residual & 118 & 0.5649 & 0.0048 & & \\
Lack of Fit & 13 & 0.1390 & 0.0107 & $2.63 *$ & 1.84 \\
Pure Error & 105 & 0.4260 & 0.0041 & &
\end{tabular}

Regression Equation: $\quad y=1.0553+0.0063 x, \quad r^{2}=0.135$ 


\section{APPENDIX 6 cont'd}

Mean Internal Pressure (Ip; $\mathrm{Pa} \cdot 10^{5}$ ) vs. Variance in Ip with Water Temperature and Velocity Constant.

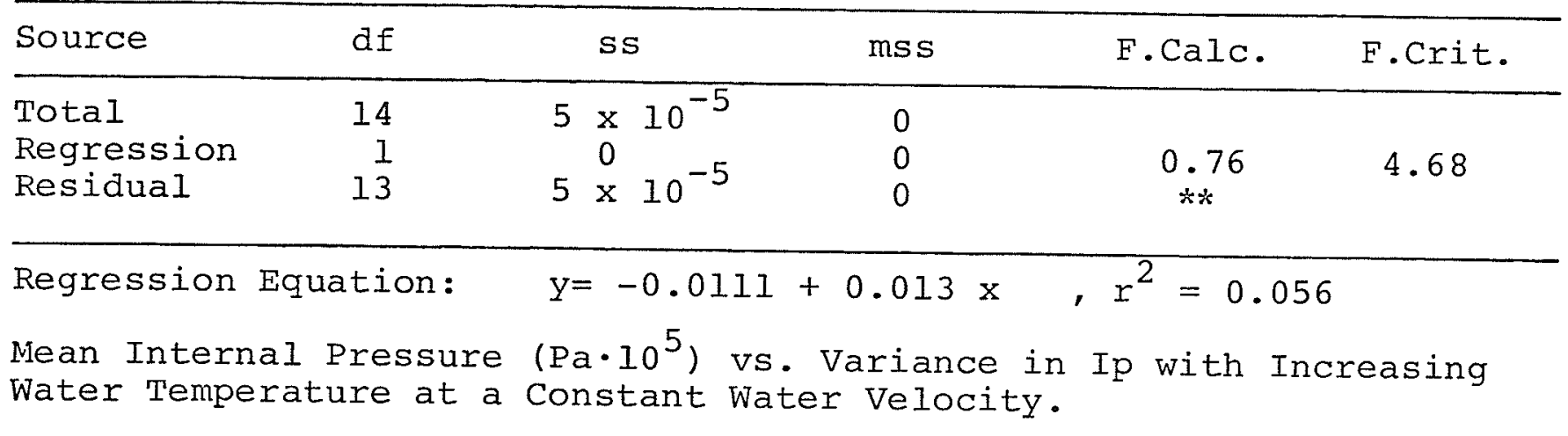

\begin{tabular}{lrcccc}
\hline Source & df & ss & mss & F.Calc. & F.Crit. \\
\hline Total & 13 & 0.0006 & $4 \times 10^{-5}$ & & \\
Regression & 1 & 0.0005 & 0.0005 & $89.44^{*}$ & 4.75 \\
Residual & 12 & 0.0001 & $1 \times 10^{-5}$ & & 3.87 \\
Lack of Fit & 10 & 0.0001 & $1 \times 10^{-5}$ & 1.94 \\
Pure Error & 2 & 0.0001 & 0 & & \\
\hline
\end{tabular}

Regression Equation: $\quad y=-0.1723+0.1629 x, r^{2}=0.882$

Mean Internal Pressure $\left(\mathrm{Pa} \cdot 10^{5}\right)$ vs. Variance in Ip with Increasing Water Velocity at a Constant Temperature.

\begin{tabular}{lrclcl}
\hline Source & df & ss & mss & F.Calc. & F.Crit. \\
\hline Total & 14 & 0.0027 & 0.0002 & & \\
Regression & 1 & 0.0022 & 0.0022 & $48.26 *$ & 4.68 \\
Residual & 13 & 0.0006 & $4 \times 10^{-5}$ & $* *$ &
\end{tabular}

Regression Equation: $y=-0.1726+0.1667 \mathrm{x}, \mathrm{r}^{2}=0.788$

Mean Internal Pressure $\left(\mathrm{Pa} \cdot 10^{5}\right)$ vs. Variance in Ip with Increasing Temperature and Water Velocity.

\begin{tabular}{lrllll}
\hline Source & df & ss & mss & F.Calc. & F.Crit. \\
\hline Total & 14 & 0.0001 & $1 \times 10^{-5}$ & & \\
Regression & 1 & 0.0001 & $7 \times 10^{-5}$ & $19.76 *$ & 4.68 \\
Residual & 13 & $4 \times 10^{-5}$ & 0 & $* \star$ &
\end{tabular}

Regression Equation: $y=-0.0456+0.0458 x, r^{2}=0.603$ ** No repeats lack of fit tests not possible. 